\title{
Protein kinase Gin4 negatively regulates flippase function and controls plasma membrane asymmetry
}

\author{
Françoise M. Roelants, Brooke M. Su, Joachim von Wulffen, Subramaniam Ramachandran, Elodie Sartorel, \\ Amy E. Trott, and Jeremy Thorner
}

Division of Biochemistry, Biophysics and Structural Biology, Department of Molecular and Cell Biology, University of California, Berkeley, CA 94720

$\mathrm{P}$ lasma membrane function requires distinct leaflet lipid compositions. Two of the P-type ATPases (flippases) in yeast, Dnf1 and Dnf2, translocate aminoglycerophospholipids from the outer to the inner leaflet, stimulated via phosphorylation by cortically localized protein kinase Fpk1. By monitoring Fpkl activity in vivo, we found that Fpk1 was hyperactive in cells lacking Gin4, a protein kinase previously implicated in septin collar assembly. Gin4 colocalized with Fpk1 at the cortical site of future bud emergence and phosphorylated Fpk1 at multiple sites, which we mapped. As judged by biochemical and phenotypic criteria, a mutant (Fpk $1^{11 \mathrm{~A}}$ ), in which 11 sites were mutated to Ala, was hyperactive, causing increased inward transport of phosphatidylethanolamine. Thus, Gin4 is a negative regulator of Fpk1 and therefore an indirect negative regulator of flippase function. Moreover, we found that decreasing flippase function rescued the growth deficiency of four different cytokinesis mutants, which suggests that the primary function of Gin4 is highly localized control of membrane lipid asymmetry and is necessary for optimal cytokinesis.

\section{Introduction}

A eukaryotic plasma membrane (PM) is a complex structure in which a multitude of lipid species are arranged in a spatially defined manner. PM lipids are organized laterally in the plane of the membrane into microdomains (Lingwood and Simons, 2010) and also transversely across the membrane, such that each leaflet of the bilayer has a distinct lipid composition (Fadeel and Xue, 2009). The marked difference in leaflet lipid content (referred to as bilayer asymmetry) was first noted in the erythrocyte PM (Gordesky and Marinetti, 1973), but is characteristic of the PM in all cell types (Devaux, 1991; van Meer, 2011). The exocellular leaflet is enriched in phosphatidylcholine, sphingolipids, and glycolipids, whereas the inner leaflet is enriched in phosphatidylethanolamine (PtdEth), phosphatidylserine (PtdSer),

Correspondence to Jeremy Thorner: jthorner@berkeley.edu

B.M. Su's present address is School of Medicine, University of California, San Francisco, San Francisco, CA 94143.

J. von Wulffen's present address is Institute for System Dynamics, University of Stuttgart, Stuttgart 70569, Germany.

A.E. Trott's present address is School of Medicine, University of Texas Health Sciences Center, Houston, TX 77030.

Abbreviations used in this paper: 5-FOA, 5-fluoro-orotic acid; AMR, actomyosin ring; CIP, calf intestinal phosphatase; GAP, GTPase-activating protein; MIPC, mannosyl-inositol-phosphorylceramide; Myr, myriocin; PHS, phytosphingosine; PM, plasma membrane; PS, primary septum; PtdEth, phosphatidylethanolamine; Ptdlns, phosphatidylinositol; PtdSer, phosphatidylserine. phosphatidylinositol (PtdIns), and derived phosphoinositides (e.g., PtdIns4,5P 2 ; Devaux, 1991; Fadeel and Xue, 2009).

Bilayer asymmetry does not arise de novo during PM biogenesis, but is generated, in part, by active translocation of PtdEth and PtdSer inwards ("flipping") along with similar translocation outwards of exoleaflet lipids ("flopping"; Daleke, 2003; van Meer, 2011). Maintenance of bilayer asymmetry is necessary in the face of the PM remodeling that results from continual exocytic vesicle insertion and endocytic vesicle removal, which would otherwise scramble leaflet lipid content. In eukaryotes, inward translocation of PtdEth and PtdSer is catalyzed by a subfamily (class 4) of P-type ATPases, dubbed flippases (Daleke, 2007; Lenoir et al., 2007; Tanaka et al., 2011; Sebastian et al., 2012). In budding yeast, there are five flippases: Dnf1, Dnf2, Dnf3, Drs2, and Neo1 (Catty et al., 1997). Dnf1 and Dnf2 localize primarily in the PM, whereas Dnf3, Drs2, and Neo1 are mainly confined to intracellular membranes (Daleke, 2007). Exit of Dnf1 (1,571 residues) and Dnf2 (1,612 residues) from the ER and their insertion and function in the PM requires their association with a smaller

(C) 2015 Roelants et al. This article is distributed under the terms of an AttributionNoncommercial-Share Alike-No Mirror Sites license for the first six months after the publication date (see http://www.rupress.org/terms). After six months it is available under a Creative Commons License (Attribution-Noncommercial-Share Alike 3.0 Unported license, as described at http://creativecommons.org/licenses/by-nc-sa/3.0/). 

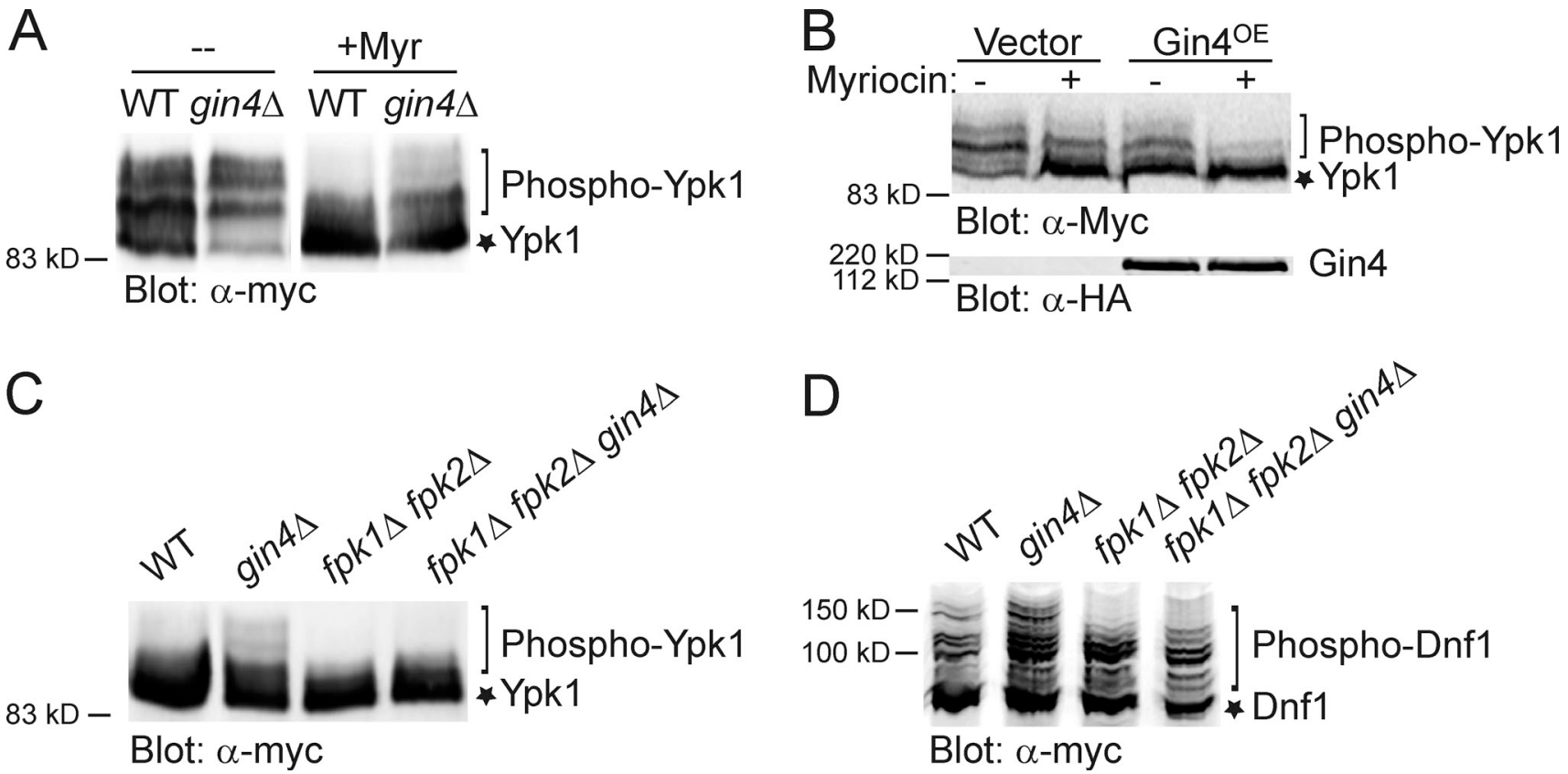

Figure 1. Gin4 negatively regulates Fpk1-dependent phosphorylation of Ypk1 and Dnf1. (A) Wild-type (WT) strain (BY4741) or an isogenic gin44 mutant (YAT1 00) expressing Ypk 1-myc from the GAL 1 promoter (pAM76) were grown to mid-exponential phase, then either mock-treated or treated with Myr $(1.25 \mu \mathrm{M})$ as indicated, collected, and lysed. The resulting extracts were resolved by SDS-PAGE and analyzed by immunoblotting with anti-c-myc mAb 9E 10. (B) As in A, except that wild-type cells (Y258) carried both a plasmid expressing Ypk 1-myc from the GAL 1 promoter (pAM54) and either an empty vector (BG 1805) or the same vector expressing Gin4 (pGin4-zz) from the GAL1 promoter. Gin4-zz was detected via its zz tag using an anti-HA

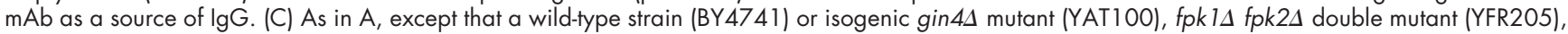

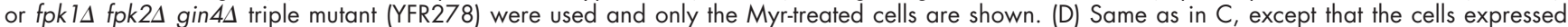
Dnf1(1403-1571)-myc from plasmid pES10 and the extract was analyzed using a Phos-tag gel.

escort protein, Lem3/Ros3 (414 residues; Kato et al., 2002; Noji et al., 2006). Genetic analysis in yeast has implicated Dnf1 and Dnf2, and the other flippases - and thus membrane asymmetry - in endocytosis, protein trafficking, and vesicle formation (Chen et al., 1999; Gall et al., 2002; Hua et al., 2002; Pomorski et al., 2003; Liu et al., 2007; Natarajan et al., 2009; Hachiro et al., 2013) and in establishment of cell polarity (Iwamoto et al., 2004; Saito et al., 2007; Fairn et al., 2011; Das et al., 2012). Mutations in the human homologue of Dnf1 and Dnf2, ATP8B1, result in progressive familial intrahepatic cholestasis (Byler disease), as well as benign recurrent intrahepatic cholestasis and intrahepatic cholestasis in pregnancy (van der Mark et al., 2013).

The role of flippases in polarized growth is particularly intriguing. PtdEth is enriched in the exocellular leaflet at sites of polarized growth (Iwamoto et al., 2004; Saito et al., 2004), which suggests that flippase function must be temporally downregulated during early bud formation when highly directional growth is required, but then reactivated when isotropic growth needs to resume. Until recently, there was little understanding about whether and how flippase function is regulated. For Drs2, specifically, it has been reported that PtdIns4P binds to its C-terminal tail and is required for its activity (Natarajan et al., 2009). The first clue about how Dnf1 and Dnf2 might be regulated came when it was found that loss-of-function mutations in FPK1, encoding a Ser/Thr protein kinase, were synthetically lethal with a deletion of $C D C 50$, which encodes a Lem3 paralogue that associates with and is required uniquely for the function of flippase Drs2 (Nakano et al., 2008), which suggests that Fpk1 action was needed for optimal activity of the remaining flippases. Indeed, yeast cells lacking Fpk1 and its paralogue Fpk2/Kin82 did not have any change in flippase abundance or localization, yet showed a reduced ability to internalize fluorescently labeled PtdEth and PtdSer derivatives and exhibited an elongated bud phenotype with prolonged exocellular PtdEth exposure (Nakano et al., 2008). Moreover, purified Fpk1 was capable of direct phosphorylation of all yeast flippases (except Neo1), but with a marked preference for Dnf1 and Dnf2 (Nakano et al., 2008). Together, these results implicate Fpk1-mediated phosphorylation as a primary stimulus of Dnf1 and Dnf2 activity, providing the first mechanistic insight about cellular control of membrane asymmetry.

Subsequently, we enlarged this regulatory circuitry by showing that Fpk1 (the closest mammalian homologue is $\mathrm{p} 70^{\mathrm{S} 6 \mathrm{~K}}$; Hunter and Plowman, 1997) is, in turn, phosphorylated and inactivated by Ypk1 (Roelants et al., 2010), a protein kinase whose function is up-regulated in response to membrane stress (Roelants et al., 2011) and which we previously showed is the sequence homologue and functional orthologue of mammalian serum- and glucocorticoid-inducible kinase (SGK1; Casamayor et al., 1999). Additionally, we showed that a complex sphingolipid species, mannosyl-inositol-phosphorylceramide (MIPC), is required for Fpk1 activity (Roelants et al., 2010). Although these observations uncovered novel inputs into Fpk1 regulation, they did not explain how Fpk1-dependent regulation of flippases is controlled spatially and temporally during passage 
through the cell division cycle to control the budding process. By the means described here, we found that a septin-associated protein kinase, Gin4, phosphorylates and negatively regulates Fpk1, allowing us to demonstrate that Gin4 is responsible for the negative regulation of aminophospholipid flipping at the incipient bud site. Moreover, Gin4-mediated inhibition of Fpk1 action appears to be necessary for efficient cytokinesis.

\section{Results}

Screening for novel Fpk1 regulators

Flippase function requires activating phosphorylation by Fpk1 (Nakano et al., 2008), a protein kinase located at the bud cortex and under negative control by protein kinase Ypk1 (Roelants et al., 2010). To identify additional potential regulators of aminophospholipid flipping, we asked whether any other protein kinase might affect Fpk1 activity. Fpk1 not only phosphorylates flippases (large proteins hard to extract from the PM), but also feedback phosphorylates Ypk1 at S51 and/or S71 (or both), leading to multiple, slower mobility Ypk1 phospho-isoforms resolvable by SDS-PAGE (Roelants et al., 2010). We have demonstrated previously that a Ypk1 mobility shift provides a convenient and reliable assay for Fpk1 activity in vivo (Roelants et al., 2010). Hence, to identify other protein kinases that may influence Fpk1 function, we expressed Ypk1-myc in a collection of strains each deleted for a nonessential protein kinase gene. Strikingly, Ypk1 phospho-isoforms were substantially increased in gin $4 \Delta$ cells (Fig. 1 A), which suggests that Gin4 may negatively regulate Fpk1. Complex sphingolipid MIPC promotes Fpk1 activity in vivo (Roelants et al., 2010). Accordingly, treatment of cells with myriocin (Myr), a drug that potently inhibits all sphingolipid biosynthesis by blocking the first enzyme (L-serine:palmitoyl-CoA C-palmitoyltransferase; SPT) in the pathway, greatly reduced the Ypk1 mobility shift. However, in cells lacking Gin4, the effect of reducing MIPC-dependent stimulation of Fpk1 was partially alleviated (Fig. $1 \mathrm{~A}$ ), which indicates that the down-regulation of Fpk1 activity by Gin4 is not mediated through any effect on the MIPC level.

Conversely, and in agreement with an independent role for Gin4 action in down-regulating Fpk1 activity, Gin4 overexpression markedly decreased the Ypk1 mobility shift and was additive with the effect of Myr (Fig. 1 B). Moreover, this effect was specific to Gin4 because elevated expression of neither its closest paralogue (Kcc4) nor its next closest relative (Hsl1), both septin-associated protein kinases (Barral et al., 1999; Shulewitz et al., 1999), like Gin4 (Longtine et al., 1998), had no effect on Ypk1 phospho-isoforms (Fig. S1). Furthermore, the increase in slower mobility Ypk1 isoforms seen in the absence of Gin4 was totally dependent on the presence of active Fpk1 and Fpk2 (Fig. 1 C), confirming that a primary role of Gin4 is to inhibit Fpk1. Although the pattern of phosphorylation of the PM flippases is much more complicated, we verified that loss of Gin4 also increased Fpk1-mediated phosphorylation of Dnf1, especially the appearance of the slowest mobility phosphoisoforms (Fig. 1 D), which further corroborates negative regulation of Fpk1 by Gin4.
Gin4 phosphorylates Fpk 1

Gin4-dependent modification of Fpk1 could be direct or indirect, and could impede Fpk1 function by affecting its localization, level, or catalytic activity. We showed previously that Fpk1 localizes to the cell cortex in young buds and to the bud neck in large budded cells (Roelants et al., 2010). Compared with GIN4 cells, the pattern of Fpk1 localization was not detectably different in cells lacking Gin4 or overexpressing Gin4 (Fig. S2 A). Likewise, compared with GIN4 cells, the steadystate level of Fpk1 was not detectably different in cells lacking or overexpressing Gin4 (Fig. S2 B). Together, these results suggested that the primary effect of Gin 4 might be to control the activity of Fpk1.

To assess whether phosphorylation of Fpk1 is Gin4 dependent in vivo, we first analyzed the migration pattern of Fpk1 fused to GFP using phosphate affinity (Phos-tag) gels (Kinoshita et al., 2009) and found a readily detectable level of a slower mobility Fpk1-GFP species whose appearance required Gin4 (Fig. 2 A, middle). This isoform was indeed due to phosphorylation because it was eliminated by treatment of the samples with calf intestinal phosphatase (CIP; Fig. 2 A, left), but persisted in the presence of CIP and the phosphatase inhibitor $\mathrm{Na}_{3} \mathrm{VO}_{4}$ (Fig. 2 A, right). To determine whether the Gin4-dependent phosphorylation of Fpk1-GFP observed in vivo may be direct, we tested whether Fpk1 serves as a substrate of Gin4 in vitro. To avoid any possibility of self-phosphorylation, catalytically inactive GST-Fpk1(D621A) (Roelants et al., 2010) purified from Escherichia coli was incubated with purified recombinant GST-Gin4 or an equivalent amount of a catalytically inactive mutant, GST-Gin4(K48A). We found that Fpk1 was readily phosphorylated by Gin4 (Fig. 2 B). Furthermore, when fused to GST, the N-terminal noncatalytic domain of Fpk1 was a much more robust substrate for Gin4 than its C-terminal (kinase) domain (Fig. 2 C). After exhaustive in vitro phosphorylation of Fpk1(1-472) by Gin4 in vitro, the sites of phosphorylation were mapped by mass spectrometry. This analysis revealed that 17 Ser or Thr residues were detectably modified, the majority of which fit the consensus (-R/KxxS-; Fig. S2 C), in accord with the phosphoacceptor site motif preference of Gin4 determined using synthetic peptide arrays (Mok et al., 2010). 11 of the most efficiently phosphorylated sites in Fpk1(1-472) were mutated to Ala, which decreased phosphorylation to a near-background level (Fig. 2 D), confirming that these sites were Gin4 targets.

\section{Gin4-mediated phosphorylation \\ down-regulates Fpk1 activity}

To determine whether a lack of Gin4-mediated phosphorylation enhances Fpk1 activity, we first examined by SDS-PAGE the mobility of Ypk1 isolated from wild-type cells or an isogenic strain in which the endogenous FPK1 locus was replaced by an allele $\left(F p k 1^{11 \mathrm{~A}}\right)$ in which the $11 \mathrm{Gin} 4$ sites in full-length Fpk1 were mutated to Ala. We found that Fpk $1^{11 \mathrm{~A}}$ greatly enhanced formation of the slower mobility phospho-isoforms compared with the control cells, even when the levels of MIPC were reduced by Myr treatment (Fig. 3 A), and this increase was comparable to that observed in gin $4 \Delta$ cells (Fig. 1 A). Likewise, compared with control cells, the appearance of the 


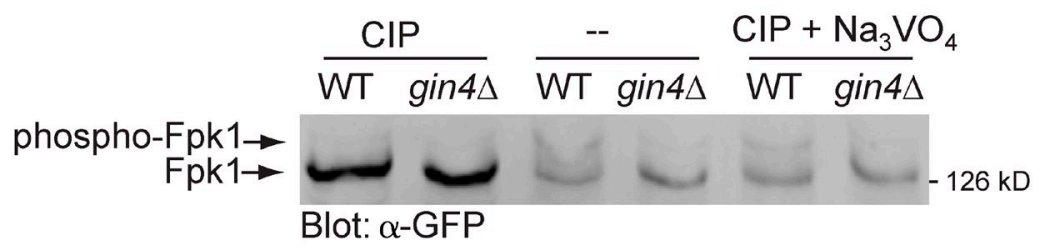

B

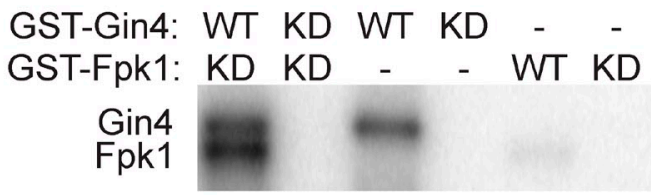

Autoradiogram

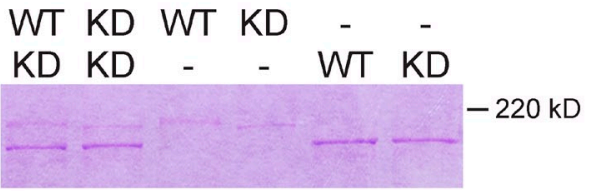

Coomassie
C

\section{GST-Gin4: WT WT WT WT GST-Fpk1: N}

Gin4

Fpk1(1-472) [N] Fpk1(473-893) [C]

\section{Autorad. Coomassie}

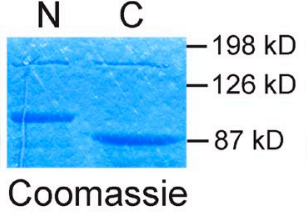

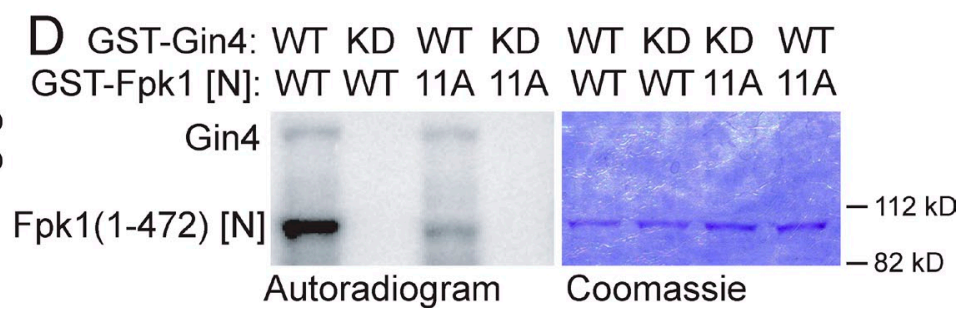

Figure 2. Gin4 phosphorylates Fpk 1 in vivo and in vitro. (A) Wild-type strain (YFR221, WT) or an isogenic gin4A (YFR224) expressing Fpk 1-GFP were grown to mid-exponential phase and lysed. The resulting extracts were either not treated or treated with $\mathrm{CIP}$ or $\mathrm{CIP}+\mathrm{Na}_{3} \mathrm{VO}_{4}$, resolved on a Phos-tag gel, and analyzed by immunoblotting with anti-GFP antibody. (B) GST-Gin4 (pAB1, WT) or catalytically inactive ("kinase-dead," KD) mutant, GST-Gin4(K48A) (pAT103), were purified from $E$. coli, incubated with $\gamma$-[32P]ATP and either GST-Fpk 1 (pFR 143, WT) or catalytically inactive (KD) mutant GST-Fpk 1 (D62 1A) (pFR 144), also purified from E. coli. Resulting products were resolved by SDS-PAGE and analyzed by autoradiography (left) and staining with Coomassie dye (right). (C) GST-Gin4 (pAB1, WT) was purified from E. coli, incubated with $\gamma-{ }^{32}$ P]ATP and either GST-Fpk 1 (1-472) (pBS1, N) or catalytically inactive GST-Fpk1 (473-893; D621A) (pBS2, C), which were also purified from E. coli, and the products were analyzed as in B. (D) As in C, except that either GSTGin4 (pAB1, WT) or catalytically inactive (KD) GST-Gin4(K48A) (pAT103) were incubated with either GST-Fpk1 (1-472) (pBS1, WT) or GST-Fpk1 (1-472;

$11 \mathrm{~A}$ ) in which 11 Gin4 phosphorylation sites were mutated to Ala (pJW2).

A
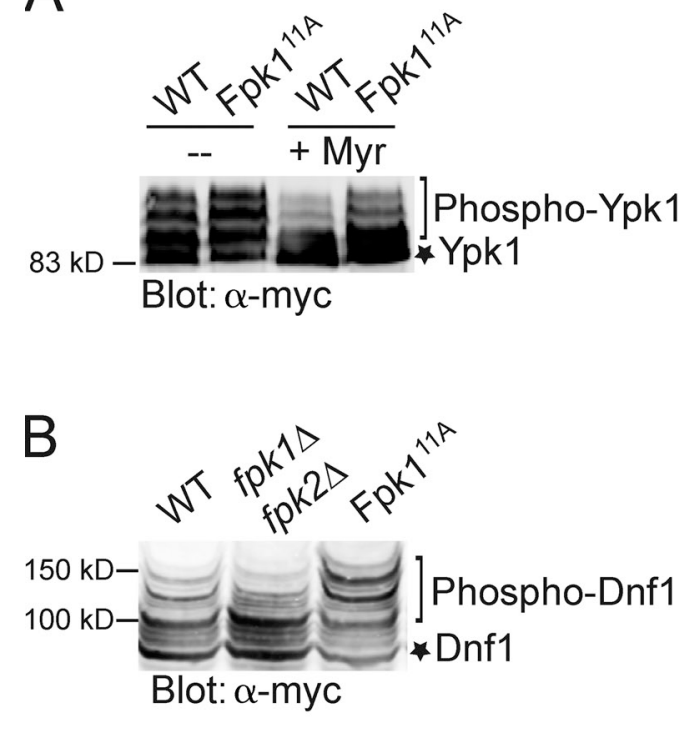

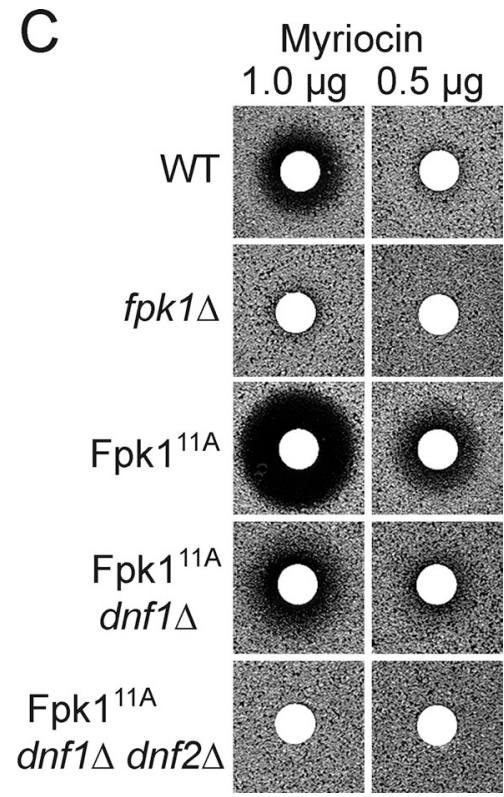

Figure 3. Phosphorylation by Gin4 down-regulates Fpk1 activity. (A) Cells expressing either wild-type Fpk 1 (BY4741, WT) or Fpk 1 11A (YJW2) and also expressing Ypk 1-myc from the GAL 1 promoter (pAM76) were grown to mid-exponential phase, untreated or treated with Myr (1.25 $\mu M)$, and lysed. The resulting extracts were resolved by SDS-PAGE and analyzed by immunoblotting with anti-c-myc mAb 9E10. (B) Cells expressing wild-type Fpk1 (BY4741,

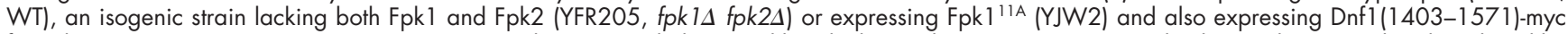
from the GAL1 promoter (pES10) were grown to mid-exponential phase and lysed. The resulting extracts were resolved on a Phos-tag gel and analyzed by

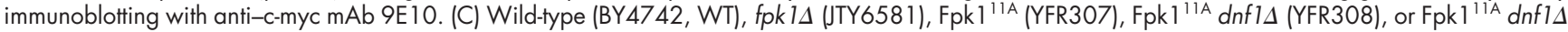
dnf2L (YFR3 12) strains, as indicated, were plated as a lawn on YPD plates and then overlaid immediately at the center with a sterile filter paper disk onto which a solution containing the indicated amounts of Myr had been spotted. After incubation at $30^{\circ} \mathrm{C}$ for $2 \mathrm{~d}$, plates were photographed. 


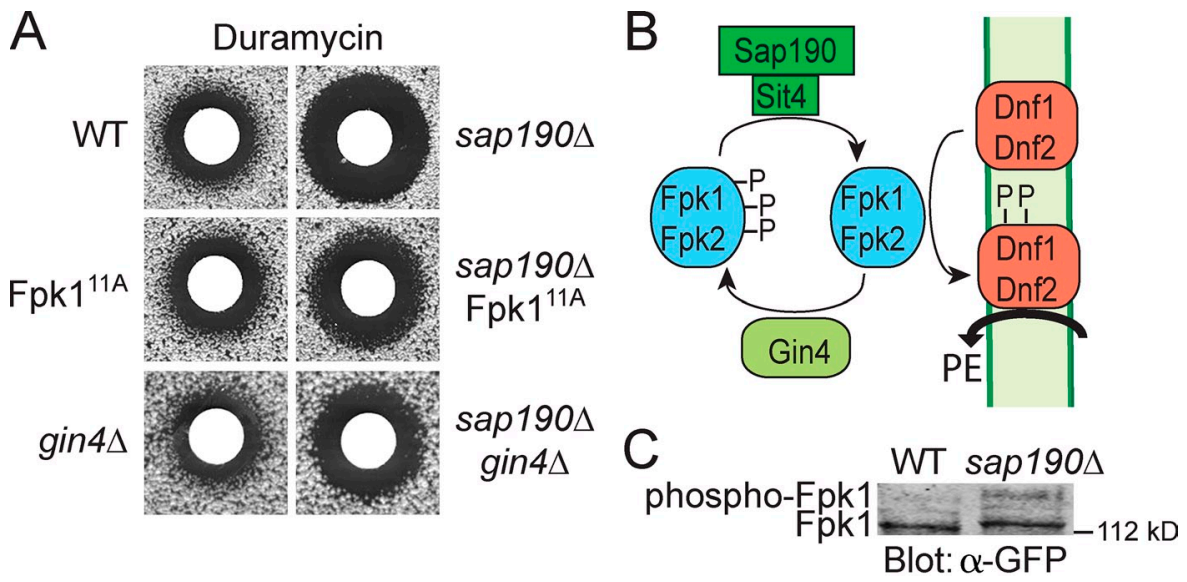

Figure 4. Gin4 phosphorylation of Fpk 1 results in down-regulation of flippase activity. (A) Wild-type (BY4741, WT), Fpk 111A (YJW2), or gin4A (YAT1 00) cells, or isogenic derivatives of the same strains carrying a sap 1904 mutation (sap1904 [YFR320], sapl904 Fpk $1^{11 \mathrm{~A}}$ [YFR323], and sap1904 gin44 [YFR326]), were plated as a lawn on YPD plates and then overlaid immediately at the center with a sterile filter paper disk onto which $10 \mu \mathrm{l}$ of a stock solution of duramycin $(8 \mathrm{mM})$ had been spotted. After incubation at $30^{\circ} \mathrm{C}$ for $3 \mathrm{~d}$, plates were photographed. (B) Model for control of Fpk 1 (and Fpk2)-dependent activation of flippases Dnf1 and Dnf2 by Gin4-mediated phosphorylation and Sit4-Sap190 dephosphorylation of Fpk 1. Trapping of Fpk 1 (and Fpk2) in their Gin4-phosphorylated state prevents optimal flippase function, increasing the level of PtdEth in the outer leaflet of the PM, thereby conferring greater sensitivity to duramycin. (C) Either wild-type cells (YFR221, WT) or an isogenic sap 1904 mutant (YFR328) expressing Fpk 1-GFP were grown to mid-exponential phase and lysed. The resulting extracts were resolved on a Phos-tag gel and analyzed by immunoblotting with anti-GFP antibody.

slowest mobility Fpk1-dependent isoforms of the flippase Dnf1 were also markedly increased in the cells expressing Fpk111A (Fig. 3 B). Thus, absence of Gin4 phosphorylation increased the specific activity of Fpk1 in vivo on both substrates. As a third criterion to assess its level of activity, we examined the Myr sensitivity conferred by Fpk $1^{11 \mathrm{~A}}$ compared with wildtype Fpk1 because we have shown previously that cells lacking Fpk1 are quite resistant to Myr (Roelants et al., 2010). Consistent with the conclusion that Fpk $1^{11 \mathrm{~A}}$ is hyperactive, the cells expressing Fpk $1^{11 \mathrm{~A}}$ cells were markedly more sensitive to Myr than cells expressing wild-type Fpk1 (Fig. 3 C). Moreover, in agreement that this phenotype was exerted through Fpk1-mediated stimulation of the flippases, the elevated drug sensitivity caused by Fpk $1^{11 \mathrm{~A}}$ was almost eliminated in cells lacking Dnf1 and totally abrogated in cells lacking both Dnf1 and Dnf2 (Fig. 3 C). Indeed, in agreement with the observation that flippases regulate the permeability of the yeast PM to xenobiotics (Yamane-Sando et al., 2014), we found that $400 \mathrm{ng} / \mathrm{ml}$ of Myr drastically reduced formation of complex sphingolipids in wild-type cells, whereas even $600 \mathrm{ng} / \mathrm{ml}$ had no effect in $d n f 1 \Delta d n f 2 \Delta$ cells (Fig. S3 A).

Furthermore, the elevated Myr sensitivity displayed by Fpk $1^{11 \mathrm{~A}}$ cells was not attributable to enhanced Fpk1-mediated feedback inhibition of Ypk1. Ypk1 phosphorylates and inactivates Orm1 and Orm2 (Roelants et al., 2011), two major negative regulators of SPT (Breslow et al., 2010); hence, elevated Fpk1-mediated feedback inhibition of Ypk1 would be expected to impede all sphingolipid biosynthesis. However, total sphingolipid levels were not significantly altered in cells expressing Fpk $1^{11 \mathrm{~A}}$ compared with wild-type or fpkls $f p k 2 \Delta$ cells (Fig. S3 B).

\section{Gin 4 phosphorylation of Fpk 1 down-regulates flippase function}

Collectively, our results indicate that modification by Gin 4 inhibits Fpk1 function and that a major physiological consequence of this regulation is inhibition of flippase function. As further confirmation of this conclusion, we took advantage of the fact that the efficiency of flippase action can be monitored by assessing the sensitivity of cells to duramycin, a drug that binds to PtdEth in the outer leaflet of the PM and kills cells (Zhao, 2011). Because Fpk1 is a flippase activator, Gin4-mediated inhibition of Fpk1 should decrease flippase function, leaving more PtdEth on the cell surface and making cells more susceptible to duramycin, whereas cells expressing Fpk $1^{11 \mathrm{~A}}$, which is largely "immune" to Gin4 phosphorylation, or cells lacking Gin4 altogether, should have enhanced flippase function, less PtdEth in the outer leaflet, and greater resistance to duramycin. However, any differences in duramycin sensitivity between wild-type, Fpk $1^{11 \mathrm{~A}}$, and $\operatorname{gin} 4 \Delta$ cells were too subtle to reliably detect (Fig. 4 A, left). We reasoned that we might be able to "trap" more wild-type Fpk1 in its Gin4-phosphorylated state (Fig. 4 B), but not Fpk $1^{11 \mathrm{~A}}$ or Fpk1 in gin $4 \Delta$ cells, and thus enhance differences in duramycin sensitivity, if we removed the phosphatase responsible for reversing Gin4-mediated phosphorylation of Fpk1. To pinpoint any phosphatase that contributes to dephosphorylation of Fpk1, the duramycin sensitivity of a collection of deletion strains lacking each of the nonessential protein phosphatase genes or their associated factors was assessed. We found that cells lacking the phosphoprotein phosphatase 2A-related phosphatase Sit4 (Sutton et al., 1991; unpublished data) or one member of the family of Sit4-associated proteins, Sap190 (Luke et al., 1996; Fig. 4 A, right), exhibited a marked increase in sensitivity to duramycin, which suggests that the Sit4-Sap190 complex specifically dephosphorylates Fpk1. Indeed, in sap1904 cells, there was a significant increase in the level of phosphorylated Fpk1 (Fig. 4 C).

Using this sensitized sap1904 background, it was clear that either Fpk $1^{11 \mathrm{~A}}$ or the absence of Gin4 enhanced flippase function to a greater extent than wild-type Fpk1 because the cells became reproducibly less sensitive to duramycin (Fig. 4 A, right). Thus, Fpk $1^{11 \mathrm{~A}}$ (or absence of Gin4) allows Fpk1 to be more active, stimulating flippase activity, reducing PtdEth in the outside leaflet, and conferring greater duramycin resistance (Fig. 4 B). 


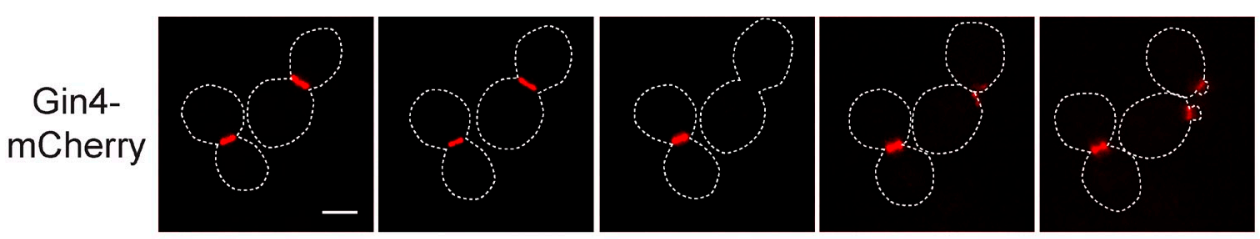

B

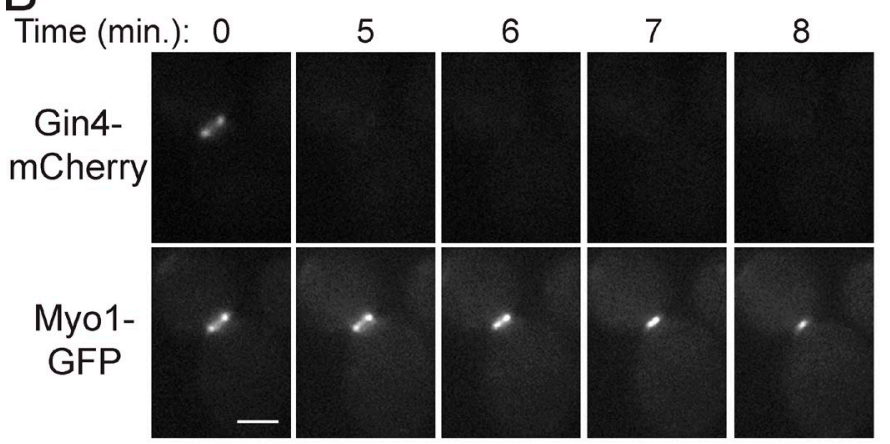

C

Time (min.):

0
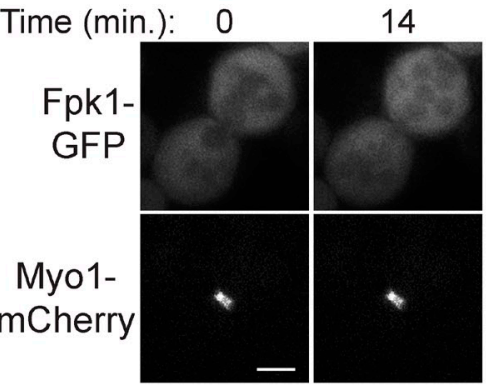

27

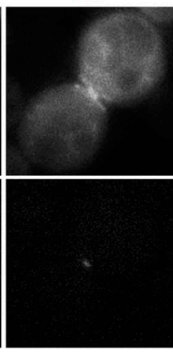

35

$\mathrm{D}$

Time (min.): 0

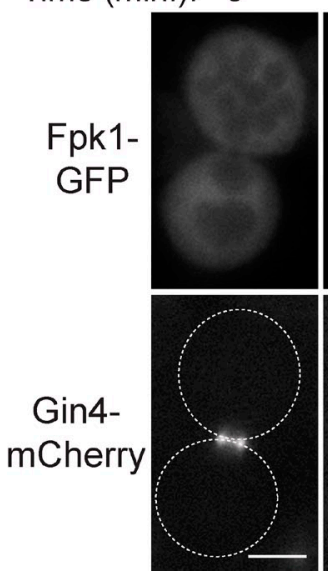

42

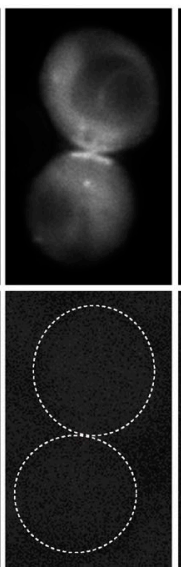

73

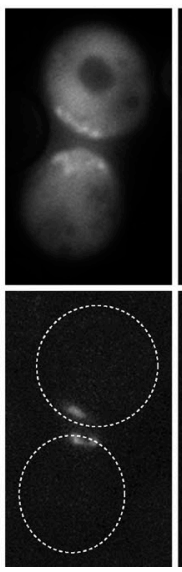

114

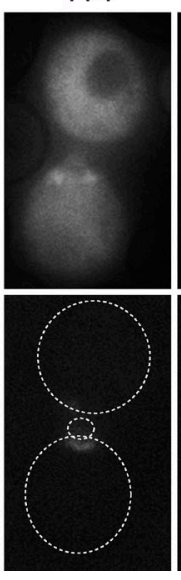

194

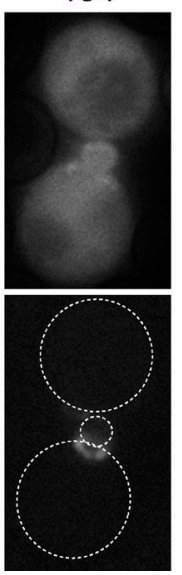

E

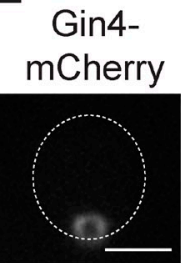

Myo1-
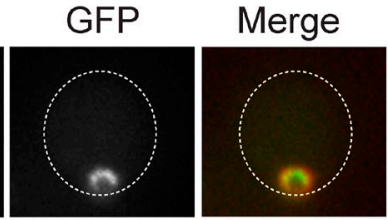

Gin4-
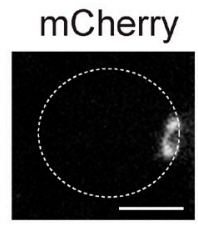

Fpk1-

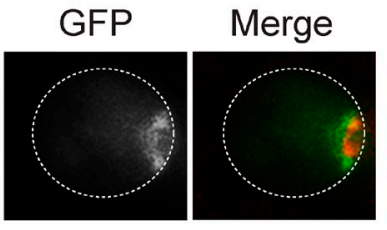

Figure 5. Gin4 and Fpk1 colocalize prominently at the site of bud emergence. (A) Cells expressing Gin4-mCherry (YFR355) were viewed by time-lapse fluorescence microscopy at 30-min intervals. (B) As in A, for cells coexpressing Gin4-mCherry and Myol-GFP (YFR388) at the indicated times. (C) As in B, for cells coexpressing Myo 1-mCherry (YFR385) and Fpk 1-GFP from the TPI1 promoter on a CEN plasmid (pFR 150). (D) As in B, for cells coexpressing Fpk 1-GFP (pFR 150) and Gin4-mCherry (YFR355). (E, top) Same cells as in B. (E, bottom) Same cells as in D. Broken lines represent the perimeter of the indicated cells. Bars, $2 \mu \mathrm{m}$.

\section{Gin 4 and Fpk1 localization indicate potential roles in cytokinesis and bud emergence}

To gain insight into the biological processes regulated by Gin4mediated inhibition of Fpk1, we first investigated the dynamics of both Gin4 and Fpk1 localization during the cell cycle. Gin4 localizes at the bud site just at bud emergence and remains at the bud neck through M-phase, then disappears before cytokinesis (Okuzaki et al., 1997; Longtine et al., 1998; Fig. 5 A). Detailed observation revealed, first, that Gin4 disappears from the bud neck before the onset of actomyosin ring (AMR) contraction, as judged by the timing of ingression of the type II myosin heavy chain (Myo1; Fig. 5 B). By the same criterion, Fpk1 accumulates at the bud neck only at the end of AMR contraction (Fig. 5 C). This reciprocal behavior suggests that increased Dnf1and Dnf2-mediated inward translocation of PtdEth may be important at the completion of cytokinesis. These observations further suggest that a function of Gin4 is to ensure complete suppression of any Fpk1-dependent flippase activation before AMR contraction and, therefore, that preventing inward PtdEth translocation is important for establishing the conditions for cytokinesis.

Furthermore, we found that Gin4 reappears at the cortical site of future bud emergence concomitant with Myo1 (Fig. S4 A), raising the possibility that Gin4 down-regulation of Fpk1 plays a role at that stage. Indeed, Fpk1 is also present at the new polarization site (Fig. 5 D), associated mainly with the perimeter of the ring-like structure containing Gin4 and Myo1 (Fig. 5 E). To confirm that Gin4-dependent inhibition of Fpk1 requires Gin4 association with the PM, we overexpressed Gin4( $\Delta 1026-1125)$, a mutant lacking its C-terminal kinase associated-1 (KA1) domain, which binds to anionic phospholipids and is required for PM and bud neck localization of Gin4 (Moravcevic et al., 2010). In contrast to overexpressed full-length Gin4 (1,142 residues), an equivalent level of Gin4( $\Delta 1026-1125)$ did not inhibit Fpk1mediated phosphorylation of Ypk1 (Fig. S4 B). Given that Dnf1 and 
Dnf2 are found at the incipient bud site (Hua et al., 2002; Pomorski et al., 2003; Saito et al., 2004), our observations suggest that, at bud emergence, Gin4 is in a position to down-regulate Fpk1 and impose a reduction in flippase activity that may be important for proper bud polarization.

Control of leaflet lipid composition is important for cytokinesis

The accumulation of Fpk1 at the bud neck at the end of AMR contraction (Fig. 5 C) prompted us to look at the potential role of Fpk1 in cytokinesis. Interestingly, in mammalian cells, there is evidence that PtdEth plays some critical role in contractile ring disassembly and completion of cytokinesis (Emoto and Umeda, 2001), whereas, in $S$. pombe, PtdEth has been implicated in the execution of cytokinesis (Luo et al., 2009). In budding yeast, it has been reported that a gin $4 \Delta$ mutation (but not a $k c c 4 \Delta$ or hslld mutation) is synthetically lethal with the absence of Hof1, an SH3 domain-containing bud neck-localized protein required for cytokinesis (Atkins et al., 2013; Meitinger et al., 2013). Based on the findings we describe here, gin $4 \Delta$ cells should have elevated Fpk1 activity and, hence, elevated flippase function. Consistent with increased flippase function being responsible for the observed lethal phenotype of gin $4 \Delta$ hofls cells, we found that Fpk $1^{11 \mathrm{~A}}$, which we showed has elevated PtdEth flipping (Fig. 4), exacerbated the temperature-sensitive growth defect of hofld cells, and, conversely, elimination of both of the flippase-activating protein kinases Fpk1 and Fpk2 almost completely rescued the growth defect of hofld cells at $37^{\circ} \mathrm{C}$ (Fig. $6 \mathrm{~A}$, top). Completely consistent with the same conclusions, increased expression of Gin4 itself potently suppressed the temperature-sensitive growth defect of hofld cells (Fig. 6 A, bottom).

Cyk3 is another SH3 domain-containing protein that interacts at the bud neck with Hof1. Although hofld cyk3s double mutants are inviable even at $30^{\circ} \mathrm{C}$ (Korinek et al., 2000), we found that absence of Fpk1 and Fpk2 partially rescued this lethality (Fig. 6 B). Likewise, absence of Inn1, a protein required for primary septum (PS) ingression at the bud neck during cytokinesis, is lethal (Nishihama et al., 2009); yet, removal of both Fpk1 and Fpk2, or removal of both flippases Dnf1 and Dnf2, rescued the inviability of innls cells (Fig. $6 \mathrm{C}$ ).

Hof1, Cyk3, and Inn1 are all needed for efficient cell division because they each participate, directly or indirectly, in activation of Chs2, the chitin synthase isoform required for PS formation (Nishihama et al., 2009; Devrekanli et al., 2012). To determine whether the suppression observed was specific to mutants defective in PS formation or would also affect mutants defective in AMR contraction, we tested myols cells, which are viable but grow very slowly (Bi et al., 1998). Remarkably, expression of Fpk $1^{11 \mathrm{~A}}$ greatly exacerbated the growth defect of cells lacking Myo1, and, conversely, elimination of Fpk1 and Fpk2 markedly improved the growth of myols cells (Fig. 6, $\mathrm{D}$ and $\mathrm{E}$ ). These results indicate that a decrease in the rate of PtdEth flipping is beneficial for cells impaired in either AMR contraction or PS formation, which suggests that during execution of normal cytokinesis and cell division, the dynamic movement of lipids in the PM needs to be properly coordinated with protein-driven events.

One predicted consequence of a decrease in Fpk1-stimulated and Dnf1- and Dnf2-catalyzed PtdEth flipping should be an increase in the activity of $\mathrm{Cdc} 42$, a key PM-associated regulator of cell polarization and cytokinesis (Tong et al., 2007; Atkins et al., 2013; Lo et al., 2013; Onishi et al., 2013), because inner leaflet PtdEth is required for activation of the GTPase-activating proteins (GAPs), Rga1 and Rga2, that down-regulate Cdc42GTP (Saito et al., 2007), and/or for the Rdi-mediated dissociation of Cdc42 from the PM (Das et al., 2012). Consistent with the idea that a contributing factor to the beneficial effect of decreased flippase function in cells impaired for cytokinesis is due to enhanced $\mathrm{Cdc} 42$ function, a modest increase in the expression of either $\mathrm{Cdc} 42$ or $\mathrm{Cdc} 24$ (Cdc42-specific guanine nucleotide exchange factor) rescued the severe growth debility of myols Fpk $1^{11 \mathrm{~A}}$ cells (Fig. $6 \mathrm{~F}$ ).

High-level overexpression of $\mathrm{Cdc} 42$ is reportedly not grossly deleterious to normal cells (Johnson and Pringle, 1990), but kills cytokinesis mutants defective in either AMR assembly or PS formation (Atkins et al., 2013); yet, as we observed for myo1s Fpk1 ${ }^{11 \mathrm{~A}}$ cells, a modest elevation in Cdc42 level markedly suppressed the temperature-sensitive growth defect of hofld cells (Fig. S5).

Collectively, our results suggest that the role of the Gin4Fpk1-flippase pathway is to properly adjust the inner leaflet PtdEth concentration as a means to fine-tune the level of active $\mathrm{Cdc} 42$ at the cell cortex. The dramatic departure of Gin4 from the bud neck that occurs just before AMR contraction would allow for Sit4-Sap190-mediated reactivation of the Fpk1 present immediately thereafter, stimulating influx of PtdEth, thereby promoting near-complete Cdc42-GTP inactivation. Consistent with this scenario, several groups have reported that a sharp drop in Cdc42-GTP occurs at the end of cytokinesis (Atkins et al., 2013; Okada et al., 2013; Kang et al., 2014).

\section{iscussion}

We have demonstrated previously (Roelants et al., 2010) that the flippase-activating protein kinase Fpk1 (and its paralogue Fpk2) is subject to two physiologically important levels of control: via inhibitory phosphorylation by the membrane-stress activated protein kinase Ypk1 (and its paralogue Ypk2); and via stimulation specifically by the complex sphingolipid MIPC (by a mechanism not yet understood). As we show here, an equally important new component of this regulatory network is inhibitory phosphorylation by the septin-associated and cell cycleregulated protein kinase Gin4 (Fig. 7). This specific function is a previously unrecognized role for Gin4, which was thought to be involved only in proper septin collar formation via direct phosphorylation of septin Shs1 (Mortensen et al., 2002; Asano et al., 2006). It has been suggested that this modification promotes formation of the septin collar that demarcates the bud neck during bud emergence, thereby generating a stable scaffold that recruits other proteins needed for bud growth and then cytokinesis (McMurray and Thorner, 2009; Oh and 

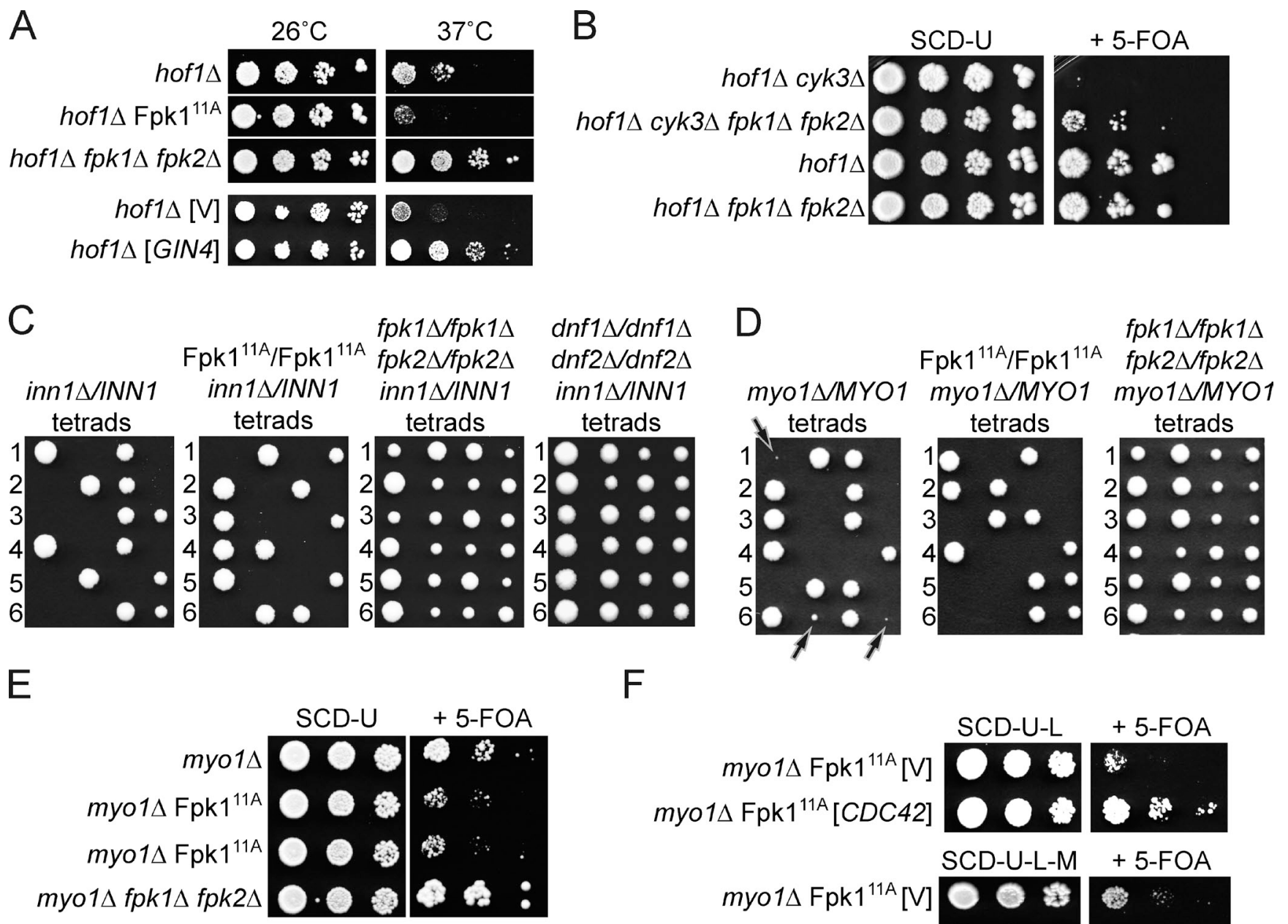

$\mathrm{F}$

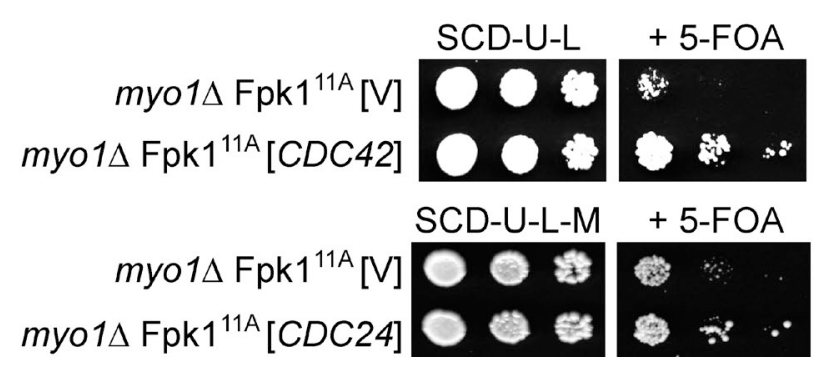

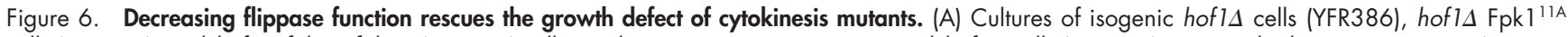

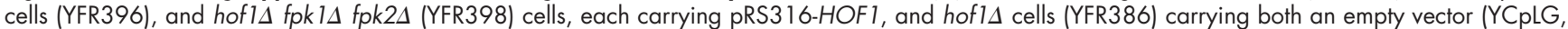
V) or the same vector expressing GIN4 (pJT5241) and pRS316-HOF1, were streaked onto plates containing 5-fluoro-orotic acid (5-FOA) medium (Boeke et al., 1984) to select against the presence of the URA3-marked pRS316-HOFl vector. Colonies arising were streaked on a second set of 5-FOA plates, and the resulting colonies were grown to mid-exponential phase in SCD. Serial 10-fold dilutions were then spotted on SCD plates. After incubation at $26^{\circ} \mathrm{C}$

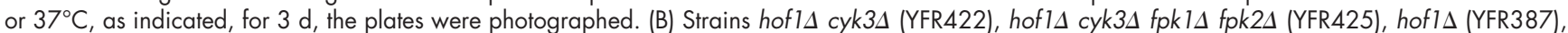
and hofl $\Delta$ fpk $1 \Delta$ fpk2 (YFR424), all carrying pRS316-HOF1, were grown to mid-exponential phase in SCD-U. Serial 10-fold dilutions were spotted on SCD-U plates and plates containing 5-FOA. After incubation at $26^{\circ} \mathrm{C}$ for $3 \mathrm{~d}$, the plates were photographed. (C) Tetrad analysis of isogenic inn $1 \Delta /$ INN 1 heterozygous diploids that were homozygous for wild-type FPK 1 (YFR421), Fpk $1^{11 \mathrm{~A}}$ (YFR419), for both fpk $1 \Delta$ and fpk2 4 (YFR414), or for both dnfl 1 and dnf24 (YFR434). (D) Tetrad analysis of isogenic myo 14/MYO1 heterozygous diploids that were homozygous for wild-type FPK1 (YFR420) or Fpk $111 \mathrm{~A}$ (YFR4 12), or for both fpk $1 \Delta$ and fpk2 (YFR413). Arrows indicate microcolonies formed by myolu spores expressing wild-type Fpk 1 (left), which are inviable when Fpk $1^{11 \mathrm{~A}}$ is present (middle) and, conversely, grow much more robustly when both Fpk 1 and Fpk2 are absent (right). (E) The same strains as in D were transformed with pRS316-MYOI and dissected on SCD-U. The resulting haploid myo IA (YFR438), myo $1 \Delta$ Fpk $1^{11 \mathrm{~A}}$ (YFR439; shown in duplicate), and myols fpk $1 \Delta$ fpk2 (YFR440) strains each carrying pRS316-MYO1 were grown to mid-exponential phase, and serial 10-fold dilutions were spotted on SCD-U plates and plates containing 5-FOA to select against the presence of the pRS3 16-MYO1 vector. After incubation at $30^{\circ} \mathrm{C}$ for $3 \mathrm{~d}$, the plates were photographed. (F) A myo 1 14 MYO1 heterozygous diploid that was homozygous for Fpk $1^{11 \mathrm{~A}}$ (YFR443) carrying an empty vector (YCpLG, V) or the same vector expressing CDC42 (PB3050), and the same strain carrying an empty vector (pRS315, V) or the same vector expressing CDC24 from the MET25 promoter (pJT4350) were transformed with pRS316-MYO1 and dissected on SCD-U-L (for the CDC42-expressing vector) or SCD-U-L-M (for the CDC24expressing vector). The resulting myol 1 Fpk $1^{11 \mathrm{~A}}$ strains (YFR448, YFR449, YFR451, and YFR452) were treated as in E.

Bi, 2011). Consistent with such a function, after mitosis, Shs1 is dephosphorylated by the Rts1-bound isoform of phosphoprotein phosphatase $2 \mathrm{~A}$, concomitant with splitting of the septin collar into two discrete rings at cytokinesis (Dobbelaere et al., 2003). However, aberrant septin structure at the bud neck is displayed by only a very small fraction of the cells in a culture of a gin $4 \Delta$ mutant (Longtine et al., 1998). Moreover, time-lapse microscopy of gin $4 \Delta$ cells expressing a GFP-tagged septin revealed that, in the majority of these rare anomalous cells, the abnormal septin morphology eventually resolves into a uniform collar and the cell then divides (McMurray and Thorner, 2009). The findings we have presented here demonstrate that Gin4 control of Fpk1 governs the level of PtdEth in the inner leaflet of the PM and argue that a fundamentally important function of Gin4 is its role in regulation of PM bilayer asymmetry.

In this regard, it must be appreciated that reversal of Gin4dependent phosphorylation of Fpk1 may also be under tight control. Although the responsible phosphatase Sit4 associates 


\section{CELL CYCLE CUES}

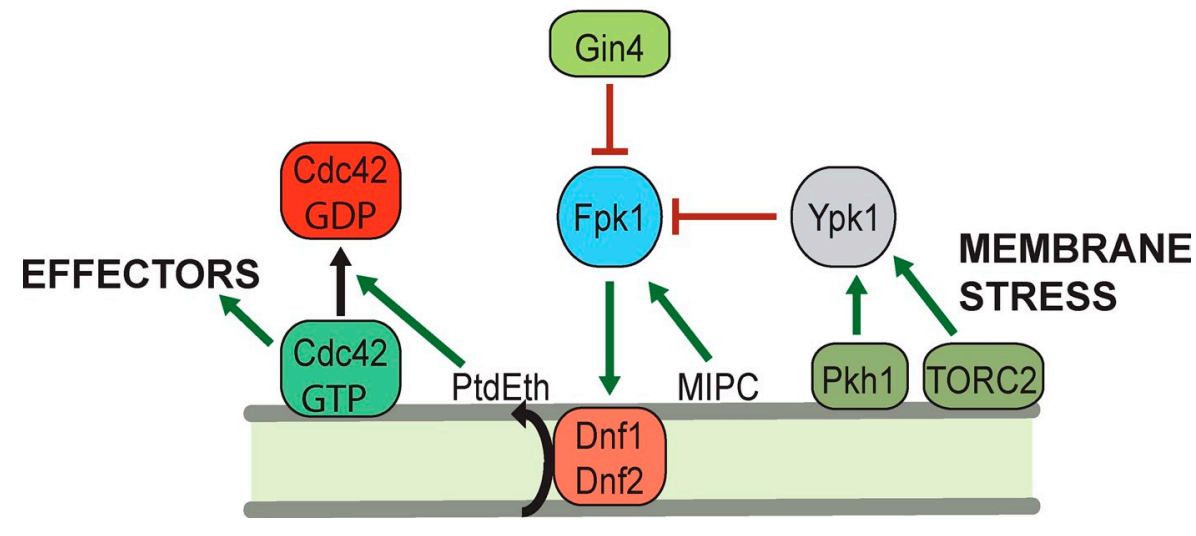

Figure 7. Gin4 controls inner leaflet PtdEth and Cdc42-GTP level. During progression through the cell cycle, Gin4 localizes at the incipient bud site, and phosphorylates and inhibits Fpk 1 at the same location, preventing flippase activation and keeping PtdEth level on the inner leaflet low. Because inner leaflet PtdEth promotes Cdc42-GTP inactivation (Saito et al., 2007; Das et al., 2012), Gin4-imposed reduction in PtdEth allows for buildup of Cdc42GTP to stimulate recruitment and function of effectors, like formin Bnil, that promote bud emergence. Further accumulation of Gin4 at the septin collar will continue to suppress the inner leaflet PtdEth level, allowing for localized protection of Cdc42-GTP, perhaps facilitating recruitment and activation of effectors required for efficient cytokinesis. Despite a normally beneficial role, flippase function also permits entry of toxic xenobiotics. To help prevent an influx of such noxious agents when the PM barrier is already compromised by heat stress or other membrane-perturbing or -damaging agents, an independent stress response mediated by protein kinase Ypkl also down-regulates flippase function by inhibiting Fpk 1. Full Ypkl activity requires its stimulation by two PM-associated protein kinases: eisosome-bound Pkh1 and the TORC2 complex.

with Sap4, Sap155, Sap185, and Sap190 (Luke et al., 1996), we

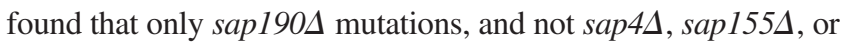
sap1854 mutations (unpublished data), exhibited an increase in duramycin sensitivity, which indicates that reactivation of Fpk1 is a function specific to only the Sap190-bound form of Sit4.

We found that, in contrast to their spatiotemporal partitioning during cytokinesis, Gin4 and Fpk1 colocalize at the incipient bud site. Given that inner leaflet PtdEth promotes inactivation of Cdc42-GTP by its GAPs and/or GDI (Cherfils and Zeghouf, 2013), our results connect Gin 4 action to modulation of the level of active Cdc42, an essential and pivotal regulator of cell polarity and morphogenesis (Etienne-Manneville, 2004; Bi and Park, 2012). Gin4, by negatively regulating Fpk1, inhibits the flippases under Fpk1 control, lowers inner leaflet PtdEth content, thus reducing PtdEth-stimulated GAP ${ }^{\mathrm{Cdc4} 2}$ (Rga1 and Rga2; Saito et al., 2007) and/or Rho GDI (Rdi1; Das et al., 2012) function, thereby maintaining or increasing the concentration of PM-associated GTP-bound Cdc42 (Fig. 7). An important aspect of the production of Cdc42-GTP above a certain threshold at this cell cycle stage is to trigger actin cable formation for bud emergence, mediated by the formin Bni1 (Chen et al., 2012). As a result of their colocalization, Gin4-mediated phosphorylation and inhibition of Fpk1 and the ensuing reduced level of inner leaflet PtdEth would allow for sufficient Cdc42-GTP at the incipient bud site for activation of this and other effectors.

Recent work has proposed a model wherein active $\mathrm{Cdc} 42$ recruits septins, which, upon assembly, inhibit Cdc42 in a negative feedback loop via the bud neck-localized Cdc42-GAPs (Okada et al., 2013). However, our findings provide deeper insight into the dynamics of this process. Assembled septins also recruit Gin4, which, by phosphorylating and inhibiting Fpk1 in its immediate vicinity, will result in down-regulation of the flippases and lowering of inner leaflet PtdEth, thereby reducing Cdc42-GAP and/or Cdc42 GDI activity, thus locally maintaining Cdc42-GTP within a tightly delimited site at the bud cortex to support bud emergence. Moreover, our visualization of these proteins showed that, at the site of bud emergence, some Fpk1 localizes in a concentric ring around the periphery of where Gin4 localizes (Fig. 5 E); if that more distant pool of Fpk1 escapes Gin4-imposed inhibition, it would be able to activate flippase function, raise inner leaflet PtdEth, stimulate Cdc42GAP and/or Cdc42-GDI activity, and thereby delineate a rather sharp boundary outside of which Cdc 42 cannot be active. Showing that there is an inverse correlation between inner leaflet PtdEth content and the concentration of active Cdc 42 is not now technically feasible because the only known PtdEth-specific probe is a fluorescently tagged derivative of a tetracyclic, disulfide-bonded peptidic antibiotic (Ro09-0198/cinnamycin) that is only able to bind this lipid when it is present in the outer leaflet of the PM (Aoki et al., 1994; Iwamoto et al., 2004). Moreover, this agent blocks PtdEth flipping and, hence, can only report the total amount of PtdEth that has been delivered to the PM.

If colocalization of Gin4 with Fpk1 suppresses flippase function during polarity establishment and bud site selection, their dramatic separation just before AMR contraction (Fig. 5) presumably achieves the opposite. Viewed in this way, Gin4 and Fpk1 provide an example of how differential spatial and temporal reorganization of components of the same signaling modality can allow for rewiring of pathway connectivity to accomplish distinct outputs during cell cycle progression. Up to the onset of cytokinesis, Gin4 is maintained at the bud neck, which, based on our data, would ensure that any residual flippase function is totally suppressed, allowing for Cdc42-GTP-stimulated processes at the bud neck, possibly Bnr1-promoted actin filament formation for AMR assembly (Vallen et al., 2000; Buttery et al., 2012). Just before initiation of AMR ingression, Gin4 rapidly disappears from the bud neck, whereas Fpk1 accumulates at the bud neck as AMR contraction is completed, which would allow for reactivation of flippases, buildup of inner leaflet PtdEth, and the downregulation of active $\mathrm{Cdc} 42$ that occurs at the end of cell division (Atkins et al., 2013; Okada et al., 2013; Kang et al., 2014).

Although we do not have direct evidence for this sort of regulation of $\mathrm{Cdc} 42$ during normal cytokinesis because roles for $\mathrm{Cdc} 42$ at this stage of the cell cycle have only recently 
started to emerge, our results indicate that regulation of $\mathrm{Cdc} 42$ exerted by the Gin4-Fpk1-flippase pathways plays a crucial role in AMR-independent cytokinesis. In the absence of Myo1, no AMR can form and PS formation is also defective, yet cytokinesis can be completed by abnormal deposition of an irregular, chitinaceous secondary septum, referred to as the remedial septum (Schmidt et al., 2002), that allows for cell separation and survival (Bi et al., 1998). We clearly show that lack of the flippase activators Fpk1 and Fpk2 ameliorates the growth defect of myols cells and that the hyperactive Fpk ${ }^{11 \mathrm{~A}}$ allele worsens the growth defect of myols cells (Fig. 6, D and E). Moreover, elimination of Fpk1 and Fpk2, or of the PM flippases they control, also ameliorated the growth defects of three different mutants (hofl $1 \Delta$, hofl $1 \Delta$ cyk3s, and inn $1 \Delta$ ) that prevent PS formation (Fig. 6, A, B, and C). Consistent with this suppression arising from increased $\mathrm{Cdc} 42$ activity due to lower inner leaflet PtdEth, modest elevation of total Cdc42 or of its GEF (Cdc24) also ameliorated the growth defect of both myol $\Delta$ cells (Fig. 6 F) and hofl 1 cells (Fig. S5). Therefore, in our hands, we find that $\mathrm{Cdc} 42$ action somehow promotes formation of this remedial septum. It is also possible that inner leaflet PtdEth influences other Rho GTPases whose overexpression has been shown to suppress the growth defect of cytokinesis mutants (Dong et al., 2003; Yoshida et al., 2009; Onishi et al., 2013).

If, in normal cells, activation of flippases and subsequent inhibition of Cdc42 is important for the completion of cytokinesis, one might wonder why the lack of flippase activity, and thus activation of $\mathrm{Cdc} 42$, is beneficial for all the mutants we tested that are defective in cytokinesis? Atkins et al. (2013) proposed that inappropriate $\mathrm{Cdc} 42$ activation during mitotic exit impairs cytokinesis via mislocalization of Inn1 and the IQGAP orthologue Iqg1, which are important for PS formation. However, in the absence of AMR or PS formation, activation of Cdc42 cannot have this deleterious effect because the proteins that are mislocalized when Cdc42 is activated are not present in the first place. Thus, the mechanism that cells use to complete cytokinesis under such conditions is different. Hence, although activation of Cdc42 may be detrimental to AMR and PS formation, our results suggest that it is beneficial with regard to remedial septum formation.

Given the central role we have uncovered for Gin4 in controlling the PtdEth content of the PM inner leaflet and, consequently, Cdc42-GTP level, one important mechanistic question to address in the immediate future is what element within Gin4 is responsible for its specific association with septin-containing structures, how it may be controlled, and, conversely, which septins or aspect of septin organization are recognized by Gin4. Another critical question is what inputs are responsible for the dramatic changes in level and localization of Gin4 during progression through the cell cycle. Gin4 has been shown to be activated by the upstream septin-associated protein kinase Elm1 (Asano et al., 2006), most likely by phosphorylation of Thr189 in its activation loop (related kinase Hsl1 is phosphorylated by Elm1 at the corresponding site, Thr273; Szkotnicki et al., 2008). Gin 4 activity and localization also appear to be modulated by Cdk1/Cdc28 (Okuzaki et al., 1997; Mortensen et al.,
2002; Holt et al., 2009). In Candida albicans, Gin4 is also phosphorylated and activated by $\mathrm{Cdk} 1$, and it has been shown that forced activation of $\mathrm{Cdc} 42$ restores defects in bud neck formation observed in gin $4 \Delta$ mutants (Li et al., 2012), placing Cdc42 downstream of the Gin4-Fpk1-flippase pathway, which is consistent with our findings. Interestingly, there is some evidence that $\mathrm{Cdc} 42$ itself is required in vivo for the mitosis-specific activation of Gin4 and the role it plays in polarized bud growth (Tjandra et al., 1998), which may represent an elegant feedback loop for regulation of the Gin4-Fpk1flippase pathway.

\section{Materials and methods}

\section{Strains and growth conditions}

Yeast strains used in this study (Table $\mathrm{S} 1$ ) were grown routinely at $30^{\circ} \mathrm{C}$. Standard rich (YP) and defined minimal (SC) media (Sherman et al., 1986), containing either $2 \%$ glucose (Glc), $2 \%$ raffinose, and $0.2 \%$ sucrose (RafSuc) or $2 \%$ galactose (Gal) as the carbon source, as indicated, and supplemented with appropriate nutrients to maintain selection for plasmids, were used for yeast cultivation. In particular, YFR433 and YFR434 (Table S1) were derived from a strain provided by T.R. Graham (Vanderbilt University, Nashville, TN). For gene induction from the GAL1 promoter, cells were pregrown to mid-exponential phase in SC+Raf-Suc medium, Gal was added (2\% final concentration), and incubation was continued for $3 \mathrm{~h}$. When cells were treated with Myr (Sigma-Aldrich) or phytosphingosine (PHS; Avanti Polar Lipids, Inc.), the cultures were grown to mid-exponential phase, induced with Gal for $1 \mathrm{~h}$, and the compounds were added at the final concentrations indicated (Myr, $1.25 \mu \mathrm{M}$; PHS, 5 or $10 \mu \mathrm{M}$ ) and incubation was continued for an additional $2 \mathrm{~h}$. Standard yeast genetic techniques were performed according to Sherman et al. (1986).

\section{Plasmids and recombinant DNA methods}

Plasmids used in this study (Table S2) were constructed using standard procedures (Sambrook et al., 1989) in E. coli strain $\mathrm{DH} 5 \alpha$. In particular, plasmid PB3050 (Table S2) was provided by D. Pellman (Harvard Medical School, Boston, MA). Fidelity of all constructs was verified by nucleotide sequence analysis. All PCR reactions were performed using Phusion DNA polymerase (Finnzymes; Thermo Fisher Scientific). Site-directed mutagenesis using appropriate mismatch oligonucleotide primers was conducted using the QuikChange method and Pfu Turbo DNA polymerase (Agilent Technologies).

\section{Preparation of cell extracts and immunoblotting}

The cells in samples $(1.5 \mathrm{ml})$ of an exponentially growing culture $\left(A_{600 \mathrm{~nm}}=\right.$ 0.6 ) were collected by brief centrifugation, immediately frozen in liquid $N_{2}$, and then lysed by resuspension in $150 \mu$ of $1.85 \mathrm{M} \mathrm{NaOH}, 7.4 \%$ $\beta$-mercaptoethanol. Protein in the resulting lysate was precipitated by the addition of $150 \mu \mathrm{l}$ of $50 \%$ trichloroacetic acid on ice. After $10 \mathrm{~min}$, the resulting denatured protein was collected by centrifugation, washed twice with acetone, and solubilized by resuspension in $80 \mu \mathrm{l}$ of $0.1 \mathrm{M}$ Tris, $5 \%$ SDS. Then, $20 \mu$ of a $5 \times$ stock of SDS-PAGE sample buffer was added. After boiling for $5 \mathrm{~min}$, portions $(15 \mu \mathrm{l})$ of the samples containing Ypk 1myc were resolved by SDS-PAGE (8\% acrylamide, 75:1 monomer-to-crosslinker), and samples containing Dnf1(1403-1571)-myc were resolved on a Phos-tag gel (8\% acrylamide, 29:1 monomer-to-cross-linker, 30 MM Phostag reagent; Wako Pure Chemical Industries), transferred to nitrocellulose, incubated with appropriate primary antibodies in Odyssey buffer (LI-COR Biosciences), washed, incubated with appropriate secondary antibodies conjugated to infrared fluorophores, and visualized using an Odyssey infrared imaging system (LI-COR Biosciences). The antibodies used in this work were: tissue culture medium containing mouse anti-c-myc mAb 9E 10, raised against a synthetic peptide corresponding to the $\mathrm{C}$-terminal residues (408-432) of human c-myc (AEEQKLISEEDLLRKRREQLKHKLE; epitope underlined) conjugated to keyhole limpet hemocyanin (1:100; Monoclonal Antibody Facility, Cancer Research Laboratory, University of California, Berkeley), mouse anti-HA mAb (1:1,000, Covance), mouse anti-GFP mAb $(1: 1,000$, Roche), and rabbit polyclonal anti-Gin4 antibodies, raised against a purified bacterially expressed $(\mathrm{His})_{6}$-tagged $\mathrm{C}$-terminal fragment (residues 870-1,142; 1:1,000, a gift of D. Kellogg, University of California, Santa Cruz, Santa Cruz, CA). 


\section{Protein kinase assay}

GST-Gin4 or a kinase-dead mutant (K68A) were expressed and purified from $E$. coli and incubated at $30^{\circ} \mathrm{C}$ in protein kinase assay buffer $120 \mathrm{mM}$ Tris- $\mathrm{HCl}, \mathrm{pH} 7.2,125 \mathrm{mM}$ potassium acetate, $12 \mathrm{mM} \mathrm{MgCl}$ $0.5 \mathrm{mM}$ EDTA, $0.5 \mathrm{mM}$ EGTA, $2 \mathrm{mM}$ DTT, 1\% glycerol, 0.02\% BSA $25 \mathrm{mM}$ B-glycerol phosphate, and $1 \mathrm{mM}$ sodium orthovanadate) with $100 \mu M \gamma-\left[{ }^{32} P\right] A T P\left(\sim 5 \times 10^{5} \mathrm{cpm} / \mathrm{nmol}\right)$ and $0.5 \mu \mathrm{g}$ of GST-fused substrate protein (which also were prepared by expression in and purification from E. coli, as described in the following section). After $30 \mathrm{~min}$, reactions were terminated by the addition of SDS-PAGE sample buffer containing $6 \%$ SDS followed by boiling for $5 \mathrm{~min}$. Labeled proteins were resolved by SDS-PAGE and analyzed by autoradiography using a Phosphorlmager (Molecular Dynamics Division, GE Healthcare).

\section{Purification of GST fusion proteins}

Freshly transformed BL21 (DE3) cells carrying a plasmid expressing the desired GST fusion protein were grown to $A_{600 \mathrm{~nm}}=0.6$, and expression was induced by the addition of isopropyl- $\beta$-D-thiogalactopyranoside (final concentrations: $0.2 \mathrm{mM}$ for GST-Fpk1 and $0.5 \mathrm{mM}$ for GST-Gin4). After vigorous aeration for $8 \mathrm{~h}$ at $26^{\circ} \mathrm{C}$ (for GST-Fpk 1) or $4 \mathrm{~h}$ at $30^{\circ} \mathrm{C}$ (for GST-Gin4), cells were harvested and the GST fusion protein was purified by column chromatography on glutathione-agarose beads using standard procedures.

\section{Analysis of complex sphingolipids}

Cells were adjusted to $A_{600 n m}=1.0 .2-m l$ cultures were labeled with $100 \mu \mathrm{Ci}$ of $\left[{ }^{32} \mathrm{P}\right] \mathrm{H}_{2} \mathrm{PO}_{4}$ and cells were allowed to grow for $3 \mathrm{~h}$. Myr was added to the overnight cultures at the indicated final concentrations from a stock of $0.625 \mathrm{mM}(250 \mathrm{pg} / \mathrm{ml})$ in methanol. An equal volume of methanol was added to the negative culture. Lipids were extracted and resolved as described previously (Momoi et al., 2004) with minor modifications. The cell pellet was washed twice with $2 \mathrm{ml}$ water and treated with $5 \%$ trichloroacetic acid for $20 \mathrm{~min}$ on ice. Pellets were extracted twice with ethanol/ water/diethyl ether/pyridine/ $\mathrm{NH}_{4} \mathrm{OH}(15: 15: 5: 1: 0.018)$ at $60^{\circ} \mathrm{C}$ for $1 \mathrm{~h}$. The combined extracts were treated with $0.1 \mathrm{~N} \mathrm{KOH}$ in methanol for $1 \mathrm{~h}$ at $50^{\circ} \mathrm{C}$ to hydrolyze glycerophospholipids. Sphingolipids then were extracted with $3 \mathrm{ml}$ chloroform, $1 \mathrm{ml}$ methanol, and $4.5 \mathrm{ml}$ of $0.5 \mathrm{~N} \mathrm{NH}_{4} \mathrm{OH}$, and the chloroform layer was washed three times with alkaline water $0.05 \mathrm{~N}$ $\mathrm{NH}_{4} \mathrm{OH}$ in water). For some samples, $1 \mathrm{ml}$ of $4 \mathrm{M} \mathrm{NaCl}$ was added during chloroform extraction to facilitate separation of the aqueous and organic phases. The organic layer was dried in a Speedvac and resuspended in $50 \mathrm{\mu l}$ of chloroform/methanol/water (16:16:5), spotted at the origin of silica gel TLC plates, and resolved by ascending chromatography using chloroform/methanol/4.2 N NH${ }_{4} \mathrm{OH}(9: 7: 2)$ as the solvent. Radioactive species on the TLC plate was visualized using a phosphorimaging screen and a Typhoon imaging system.

\section{Determination of total sphingolipids}

Overnight cultures were adjusted to $A_{600 \mathrm{~nm}}=0.2$ and allowed to grow to an $A_{600 \mathrm{~nm}}=1.0$. The cell pellet from $10 \mathrm{ml}$ of such cultures was used for analysis. Lipids were extracted, as described in the previous section, and total lipid extract was hydrolyzed with $0.5 \mathrm{M} \mathrm{HCl}$ in acetonitrile-water for $4 \mathrm{~h}$ at $70^{\circ} \mathrm{C}$. After hydrolysis, the acid was neutralized by $0.2 \mathrm{ml} \mathrm{NH}{ }_{4} \mathrm{OH}$, $1 \mathrm{ml} \mathrm{CHCl}$ and $1 \mathrm{ml}$ of water were added, solutions were mixed, phases were separated by centrifugation, and the organic layer was removed and dried in a Speedvac (Thermo Fisher Scientific). Dried lipids were resuspended in $0.3 \mathrm{ml}$ methanol and derivatized with $0.1 \mathrm{ml}$ o-phthalaldehyde, as described previously (Merrill et al., 2000). After incubation for $30 \mathrm{~min}$, the reaction was centrifuged to remove particulate matter and 20-50 $\mu$ of the supernatant was analyzed by HPLC performed using an Eclipse Plus C18 column $(4.6 \times 150 \mathrm{~mm}, 5 \mu \mathrm{m})$ on an HPLC device (120 Infinity; Agilent) equipped with a UV detector. Samples were resolved using a mobile phase gradient of methanol/5 $\mathrm{mM}$ potassium phosphate, $\mathrm{pH} 7.0$, from 50:50 (vol/vol) to 95:5 (vol/vol) over a 7-min elution. PHS, both pure standard (Avanti Polar Lipids, Inc.) and in yeast samples, was reproducibly observed as a sharp peak at $2.9 \mathrm{~min}$ with a $>1,000$-fold signal-to-noise ratio. PHS standard was serially diluted and resolved by the same method to determine the linear range of the analysis.

\section{Subcellular localization by fluorescence microscopy}

Yeast proteins fused to either GFP (Tsien, 1998) or mCherry (Shaner et al., 2004) were constructed by in-frame integration at the corresponding chromosomal locus and expressed from the endogenous promoter, except Fpk 1-GFP that was expressed from the TPII promoter on a CEN plasmid, which, as we demonstrated previously, displays a pattern of localization brighter than, but indistinguishable from, that exhibited by integrated
Fpk 1-GFP expressed from its endogenous promoter (Roelants et al., 2010). All such fusions were functional, as judged by complementation tests, i.e., the ability of an integrated construct to confer a normal phenotype or a plasmid-borne construct to restore a normal phenotype to the corresponding null mutant. To visualize yeast proteins tagged with GFP or mCherry, cells were grown to mid-exponential phase, spotted on $1 \%$ agarose pads on a glass slide at room temperature, and viewed directly under an epifluorescence microscope (model BH-2; Olympus) using a 100x objective lens (D plan Apochromat 100, 1.3 numerical aperture) equipped with appropriate band-pass filters (Chroma Technology Corp.) and illuminated with a SOLA SE Light Engine (Lumencor, Inc.) for excitation. Images were collected using a charged-couple device camera (CoolSNAP MYO; Photometrics), and processed with Micro-Manager imaging software (Edelstein et al., 2010) and Photoshop (Adobe Systems).

\section{Analysis of phosphorylation sites by mass spectrometry}

GST-Fpk 1 1-472) that was expressed and purified from E. coli was incubated exhaustively with excess Mg-ATP and GST-Gin4 that was also expressed and purified from E. coli in a standard protein kinase assay buffer (see the "Protein kinase assay" section). Portions of the phosphorylated GST-Fpk 1 were denatured in $8 \mathrm{M}$ urea, $100 \mathrm{mM}$ Tris-HCl, pH 8.5, reduced with $5 \mathrm{mM}$ tris-(2-carboxyethyl)-phosphine, amidomethylated at its sole Cys (C173) by incubation in the dark with $10 \mathrm{mM}$ freshly prepared iodoacetamide, and then concentrated fivefold using a Microcon 50 centrifugal filtration device (EMD Millipore). Portions of the resulting protein were diluted fourfold into $1 \mathrm{mM} \mathrm{CaCl} 2$ and $100 \mathrm{mM}$ Tris- $\mathrm{HCl}, \mathrm{pH} 8.5$, and digested with at final concentration of $1.5 \mu \mathrm{g} / \mathrm{ml}$ sequencing grade trypsin (Promega) or endoprotease Glu-C (Staphylococcus aureus V8 protease) at $37^{\circ} \mathrm{C}$ for at least $8 \mathrm{~h}$. Reactions were terminated by the addition of $5 \%$ formic acid (final concentration). The resulting peptides were desalted using a $\mathrm{C}_{18}$ spin tip (OMIX; Varian/Agilent Technologies). A nano LC column (consisting of $10 \mathrm{~cm}$ of $C_{18} 5$ - $\mu \mathrm{m}$ packing material; Polariz, Varian/Agilent Technologies) was packed in a 100- $\mu \mathrm{m}$ inner diameter glass capillary with an emitter tip, loaded with the sample by use of a pressure bomb, and washed extensively with Buffer A $15 \%$ acetonitrile, $0.02 \%$ heptafluorobutyric acid). The column was then directly coupled to an electrospray ionization source mounted on an LTQ XL linear ion trap mass spectrometer (Thermo Fisher Scientific). An HPLC (Model 1200; Agilent Technology) equipped with a split line, so as to deliver a flow rate of $300 \mathrm{nl} / \mathrm{min}$, was used for elution using a linear gradient from $100 \%$ Buffer $A$ to $60 \%$ Buffer B $(80 \%$ acetonitrile, $0.02 \%$ heptafluorobutyric acid). The programs SEQUEST and DTASELECT (Eng et al., 1994; Tabb et al., 2002) were used to identify peptides from the $S$. cerevisiae database, supplemented with a database of common contaminants. Spectra identified by SEQUEST as phosphopeptides were inspected manually to further assess the quality of the match.

\section{Online supplemental material}

Fig. $\mathrm{S} 1$ shows that $\mathrm{Kcc} 4$ and $\mathrm{Hsl} 1$ do not affect Fpk 1-dependent phosphorylation of Ypk1. Fig. S2 shows that Gin4 does not affect Fpk 1 localization or level and the Gin4 phosphorylation sites in Fpk 1 (1-472). Fig. S3 shows that PM flippase activity is required for susceptibility to Myr, but does not affect sphingolipid levels. Fig. S4 shows that the KA1 domain of Gin4 is required for its negative regulation of Fpkl activity. Fig. S5 shows that modest elevation of $\mathrm{Cdc} 42$ rescues hof $1 \Delta$ cells, whereas galactose-driven overexpression is toxic. Tables S1 and S2 list the yeast strains and plasmids used in this study. Online supplemental material is available at http://www.jcb.org/cgi/content/full/jcb.201410076/DC1.

We thank Todd Graham for the dnf $1 \Delta$ dnf2 $\Delta$ dnf3 $\Delta$ strain, Douglas Kellogg for anti-Gin4 antibodies, David Pellman for plasmid PB3050, Lori Kohlstaedt for expert help with mass spectrometry, Thorner laboratory members Anna Roelants and Hannah Thorner for technical assistance, and Alexander Muir, Alexander Baltz, Gregory Finnigan, and Jesse Patterson for reagents, plasmids, and useful discussions.

This work was supported by National Institutes of Health $(\mathrm{NIH}) \mathrm{RO} I$ Research grant GM21841 (to J. Thorner), by NIH Ruth L. Kirschstein National Research Service Award Postdoctoral Fellowship GM77886 (to A.E. Trott), and, in part, by NIH S 10 Instrumentation grant RRO25622 to the Vincent Coates Proteomics/Mass Spectrometry Facility at the University of California, Berkeley.

The authors declare no competing financial interests.

Submitted: 21 October 2014

Accepted: 29 December 2014 


\section{References}

Aoki, Y., T. Uenaka, J. Aoki, M. Umeda, and K. Inoue. 1994. A novel peptide probe for studying the transbilayer movement of phosphatidylethanolamine. J. Biochem. 116:291-297.

Asano, S., J.E. Park, L.R. Yu, M. Zhou, K. Sakchaisri, C.J. Park, Y.H. Kang, J. Thorner, T.D. Veenstra, and K.S. Lee. 2006. Direct phosphorylation and activation of a Nim1-related kinase Gin4 by Elm1 in budding yeast. J. Biol. Chem. 281:27090-27098. http://dx.doi.org/10.1074/jbc .M601483200

Atkins, B.D., S. Yoshida, K. Saito, C.F. Wu, D.J. Lew, and D. Pellman. 2013. Inhibition of Cdc42 during mitotic exit is required for cytokinesis. J. Cell Biol. 202:231-240. http://dx.doi.org/10.1083/jcb.201301090

Barral, Y., M. Parra, S. Bidlingmaier, and M. Snyder. 1999. Nim1-related kinases coordinate cell cycle progression with the organization of the peripheral cytoskeleton in yeast. Genes Dev. 13:176-187. http://dx.doi.org/ 10.1101/gad.13.2.176

Bi, E., and H.O. Park. 2012. Cell polarization and cytokinesis in budding yeast. Genetics. 191:347-387. http://dx.doi.org/10.1534/genetics.111.132886

Bi, E., P. Maddox, D.J. Lew, E.D. Salmon, J.N. McMillan, E. Yeh, and J.R. Pringle. 1998. Involvement of an actomyosin contractile ring in Saccharomyces cerevisiae cytokinesis. J. Cell Biol. 142:1301-1312. http://dx.doi.org/10.1083/jcb.142.5.1301

Boeke, J.D., F. LaCroute, and G.R. Fink. 1984. A positive selection for mutants lacking orotidine-5'-phosphate decarboxylase activity in yeast: 5-fluoroorotic acid resistance. Mol. Gen. Genet. 197:345-346. http://dx.doi.org/ 10.1007/BF00330984

Breslow, D.K., S.R. Collins, B. Bodenmiller, R. Aebersold, K. Simons, A Shevchenko, C.S. Ejsing, and J.S. Weissman. 2010. Orm family proteins mediate sphingolipid homeostasis. Nature. 463:1048-1053. http://dx.doi .org/10.1038/nature08787

Buttery, S.M., K. Kono, E. Stokasimov, and D. Pellman. 2012. Regulation of the formin Bnr1 by septins and a MARK/Par1-family septin-associated kinase. Mol. Biol. Cell. 23:4041-4053. http://dx.doi.org/10.1091/mbc E12-05-0395

Casamayor, A., P.D. Torrance, T. Kobayashi, J. Thorner, and D.R. Alessi. 1999. Functional counterparts of mammalian protein kinases PDK1 and SGK in budding yeast. Curr. Biol. 9:186-197. http://dx.doi.org/10.1016/S09609822(99)80088-8

Catty, P., A. de Kerchove d'Exaerde, and A. Goffeau. 1997. The complete inventory of the yeast Saccharomyces cerevisiae P-type transport ATPases. FEBS Lett. 409:325-332. http://dx.doi.org/10.1016/S0014-5793(97)00446-8

Chen, C.Y., M.F. Ingram, P.H. Rosal, and T.R. Graham. 1999. Role for Drs2p, a P-type ATPase and potential aminophospholipid translocase, in yeast late Golgi function. J. Cell Biol. 147:1223-1236. http://dx.doi.org/10.1083/ jcb.147.6.1223

Chen, H., C.C. Kuo, H. Kang, A.S. Howell, T.R. Zyla, M. Jin, and D.J. Lew. 2012. Cdc42p regulation of the yeast formin Bnilp mediated by the effector Gic2p. Mol. Biol. Cell. 23:3814-3826. http://dx.doi.org/10.1091/mbc. E12-05-0400

Cherfils, J., and M. Zeghouf. 2013. Regulation of small GTPases by GEFs, GAPs, and GDIs. Physiol. Rev. 93:269-309. http://dx.doi.org/10.1152/ physrev.00003.2012

Daleke, D.L. 2003. Regulation of transbilayer plasma membrane phospholipid asymmetry. J. Lipid Res. 44:233-242. http://dx.doi.org/10.1194/jlr.R200019JLR200

Daleke, D.L. 2007. Phospholipid flippases. J. Biol. Chem. 282:821-825. http:// dx.doi.org/10.1074/jbc.R600035200

Das, A., B.D. Slaughter, J.R. Unruh, W.D. Bradford, R. Alexander, B. Rubinstein, and R. Li. 2012. Flippase-mediated phospholipid asymmetry promotes fast Cdc42 recycling in dynamic maintenance of cell polarity. Nat. Cell Biol. 14:304-310. http://dx.doi.org/10.1038/ncb2444

Devaux, P.F. 1991. Static and dynamic lipid asymmetry in cell membranes. Biochemistry. 30:1163-1173. http://dx.doi.org/10.1021/bi00219a001

Devrekanli, A., M. Foltman, C. Roncero, A. Sanchez-Diaz, and K. Labib. 2012. Inn 1 and Cyk3 regulate chitin synthase during cytokinesis in budding yeasts. J. Cell Sci. 125:5453-5466. http://dx.doi.org/10.1242/jcs 109157

Dobbelaere, J., M.S. Gentry, R.L. Hallberg, and Y. Barral. 2003. Phosphorylationdependent regulation of septin dynamics during the cell cycle. Dev. Cell. 4:345-357. http://dx.doi.org/10.1016/S1534-5807(03)00061-3

Dong, Y., D. Pruyne, and A. Bretscher. 2003. Formin-dependent actin assembly is regulated by distinct modes of Rho signaling in yeast. J. Cell Biol. 161:1081-1092. http://dx.doi.org/10.1083/jcb.200212040

Edelstein, A., N. Amodaj, K. Hoover, R. Vale, and N. Stuurman. 2010. Computer control of microscopes using $\mu$ Manager. Curr. Protoc. Mol. Biol. Chapter $14: 20$.
Emoto, K., and M. Umeda. 2001. Membrane lipid control of cytokinesis. Cell Struct. Funct. 26:659-665. http://dx.doi.org/10.1247/csf.26.659

Eng, J.K., A.L. McCormack, and J.R. Yates. 1994. An approach to correlate tandem mass spectral data of peptides with amino acid sequences in a protein database. J. Am. Soc. Mass Spectrom. 5:976-989. http://dx.doi org/10.1016/1044-0305(94)80016-2

Etienne-Manneville, S. 2004. Cdc42-the centre of polarity. J. Cell Sci. 117:1291-1300. http://dx.doi.org/10.1242/jcs.01115

Fadeel, B., and D. Xue. 2009. The ins and outs of phospholipid asymmetry in the plasma membrane: roles in health and disease. Crit. Rev. Biochem. Mol. Biol. 44:264-277. http://dx.doi.org/10.1080/10409230903193307

Fairn, G.D., M. Hermansson, P. Somerharju, and S. Grinstein. 2011. Phosphatidylserine is polarized and required for proper Cdc42 localization and for development of cell polarity. Nat. Cell Biol. 13:1424-1430. http://dx.doi.org/10.1038/ncb2351

Gall, W.E., N.C. Geething, Z. Hua, M.F. Ingram, K. Liu, S.I. Chen, and T.R. Graham. 2002. Drs2p-dependent formation of exocytic clathrincoated vesicles in vivo. Curr. Biol. 12:1623-1627. http://dx.doi.org/10 1016/S0960-9822(02)01148-X

Gordesky, S.E., and G.V. Marinetti. 1973. The asymetric arrangement of phospholipids in the human erythrocyte membrane. Biochem. Biophys. Res. Commun. 50:1027-1031. http://dx.doi.org/10.1016/0006-291X(73)91509-X

Hachiro, T., T. Yamamoto, K. Nakano, and K. Tanaka. 2013. Phospholipid flippases Lem3p-Dnf1p and Lem3p-Dnf2p are involved in the sorting of the tryptophan permease Tat2p in yeast. J. Biol. Chem. 288:3594-3608. http://dx.doi.org/10.1074/jbc.M112.416263

Holt, L.J., B.B. Tuch, J. Villén, A.D. Johnson, S.P. Gygi, and D.O. Morgan. 2009. Global analysis of Cdk1 substrate phosphorylation sites provides insights into evolution. Science. 325:1682-1686. http://dx.doi.org/10.1126/ science. 1172867

Hua, Z., P. Fatheddin, and T.R. Graham. 2002. An essential subfamily of Drs2prelated P-type ATPases is required for protein trafficking between Golgi complex and endosomal/vacuolar system. Mol. Biol. Cell. 13:3162-3177. http://dx.doi.org/10.1091/mbc.E02-03-0172

Hunter, T., and G.D. Plowman. 1997. The protein kinases of budding yeast: six score and more. Trends Biochem. Sci. 22:18-22. http://dx.doi.org/10.1016/ S0968-0004(96)10068-2

Iwamoto, K., S. Kobayashi, R. Fukuda, M. Umeda, T. Kobayashi, and A. Ohta. 2004. Local exposure of phosphatidylethanolamine on the yeast plasma membrane is implicated in cell polarity. Genes Cells. 9:891-903. http:// dx.doi.org/10.1111/j.1365-2443.2004.00782.x

Johnson, D.I., and J.R. Pringle. 1990. Molecular characterization of CDC42, a Saccharomyces cerevisiae gene involved in the development of cell polarity. J. Cell Biol. 111:143-152. http://dx.doi.org/10.1083/jcb.111.1.143

Kang, P.J., M.E. Lee, and H.O. Park. 2014. Bud3 activates Cdc42 to establish a proper growth site in budding yeast. J. Cell Biol. 206:19-28. http:// dx.doi.org/10.1083/jcb.201402040

Kato, U., K. Emoto, C. Fredriksson, H. Nakamura, A. Ohta, T. Kobayashi, K Murakami-Murofushi, T. Kobayashi, and M. Umeda. 2002. A novel membrane protein, Ros $3 \mathrm{p}$, is required for phospholipid translocation across the plasma membrane in Saccharomyces cerevisiae. J. Biol. Chem. 277:37855-37862. http://dx.doi.org/10.1074/jbc.M205564200

Kinoshita, E., E. Kinoshita-Kikuta, and T. Koike. 2009. Separation and detection of large phosphoproteins using Phos-tag SDS-PAGE. Nat. Protoc. 4:1513-1521. http://dx.doi.org/10.1038/nprot.2009.154

Korinek, W.S., E. Bi, J.A. Epp, L. Wang, J. Ho, and J. Chant. 2000. Cyk3, a novel SH3-domain protein, affects cytokinesis in yeast. Curr. Biol. 10:947-950. http://dx.doi.org/10.1016/S0960-9822(00)00626-6

Lenoir, G., P. Williamson, and J.C. Holthuis. 2007. On the origin of lipid asymmetry: the flip side of ion transport. Curr. Opin. Chem. Biol. 11:654-661. http://dx.doi.org/10.1016/j.cbpa.2007.09.008

Li, C.R., J.Y. Au Yong, Y.M. Wang, and Y. Wang. 2012. CDK regulates septin organization through cell-cycle-dependent phosphorylation of the Nim1-related kinase Gin4. J. Cell Sci. 125:2533-2543. http://dx.doi .org/10.1242/jcs. 104497

Lingwood, D., and K. Simons. 2010. Lipid rafts as a membrane-organizing principle. Science. 327:46-50. http://dx.doi.org/10.1126/science.1174621

Liu, K., Z. Hua, J.A. Nepute, and T.R. Graham. 2007. Yeast P4-ATPases Drs2p and Dnf1p are essential cargos of the NPFXD/Sla1p endocytic pathway. Mol. Biol. Cell. 18:487-500. http://dx.doi.org/10.1091/mbc .E06-07-0592

Lo, W.C., M.E. Lee, M. Narayan, C.S. Chou, and H.O. Park. 2013. Polarization of diploid daughter cells directed by spatial cues and GTP hydrolysis of Cdc42 budding yeast. PLOS ONE. 8:e56665. http://dx.doi.org/10.1371/ journal.pone.0056665

Longtine, M.S., H. Fares, and J.R. Pringle. 1998. Role of the yeast Gin4p protein kinase in septin assembly and the relationship between septin 
assembly and septin function. J. Cell Biol. 143:719-736. http://dx.doi .org/10.1083/jcb.143.3.719

Luke, M.M., F. Della Seta, C.J. Di Como, H. Sugimoto, R. Kobayashi, and K.T. Arndt. 1996. The SAP, a new family of proteins, associate and function positively with the SIT4 phosphatase. Mol. Cell. Biol. 16:2744-2755.

Luo, J., Y. Matsuo, G. Gulis, H. Hinz, J. Patton-Vogt, and S. Marcus. 2009. Phosphatidylethanolamine is required for normal cell morphology and cytokinesis in the fission yeast Schizosaccharomyces pombe. Eukaryot. Cell. 8:790-799. http://dx.doi.org/10.1128/EC.00029-09

McMurray, M.A., and J. Thorner. 2009. Septins: molecular partitioning and the generation of cellular asymmetry. Cell Div. 4:18. http://dx.doi.org/ 10.1186/1747-1028-4-18

Meitinger, F., S. Palani, B. Hub, and G. Pereira. 2013. Dual function of the NDR-kinase Dbf2 in the regulation of the F-BAR protein Hof1 during cytokinesis. Mol. Biol. Cell. 24:1290-1304. http://dx.doi.org/10.1091/ mbc.E12-08-0608

Merrill, A.H., T.B. Caligan, E. Wang, K. Peters, and J. Ou. 2000. Analysis of sphingoid bases and sphingoid base 1-phosphates by high-performance liquid chromatography. Methods Enzymol. 312:3-9. http://dx.doi.org/ 10.1016/S0076-6879(00)12894-0

Mok, J., P.M. Kim, H.Y. Lam, S. Piccirillo, X. Zhou, G.R. Jeschke, D.L. Sheridan, S.A. Parker, V. Desai, M. Jwa, et al. 2010. Deciphering protein kinase specificity through large-scale analysis of yeast phosphorylation site motifs. Sci. Signal. 3:ra12. http://dx.doi.org/10.1126/scisignal.2000482

Momoi, M., D. Tanoue, Y. Sun, H. Takematsu, Y. Suzuki, M. Suzuki, A. Suzuki, T. Fujita, and Y. Kozutsumi. 2004. SLI1 (YGR212W) is a major gene conferring resistance to the sphingolipid biosynthesis inhibitor ISP-1, and encodes an ISP-1 N-acetyltransferase in yeast. Biochem. J. 381:321-328. http://dx.doi.org/10.1042/BJ20040108

Moravcevic, K., J.M. Mendrola, K.R. Schmitz, Y.H. Wang, D. Slochower, P.A Janmey, and M.A. Lemmon. 2010. Kinase associated-1 domains drive MARK/PAR1 kinases to membrane targets by binding acidic phospholipids. Cell. 143:966-977. http://dx.doi.org/10.1016/j.cell.2010.11.028

Mortensen, E.M., H. McDonald, J. Yates III, and D.R. Kellogg. 2002. Cell cycle-dependent assembly of a Gin4-septin complex. Mol. Biol. Cell. 13:2091-2105. http://dx.doi.org/10.1091/mbc.01-10-0500

Nakano, K., T. Yamamoto, T. Kishimoto, T. Noji, and K. Tanaka. 2008. Protein kinases Fpk1p and Fpk2p are novel regulators of phospholipid asymmetry. Mol. Biol. Cell. 19:1783-1797. http://dx.doi.org/10.1091/mbc E07-07-0646

Natarajan, P., K. Liu, D.V. Patil, V.A. Sciorra, C.L. Jackson, and T.R. Graham 2009. Regulation of a Golgi flippase by phosphoinositides and an ArfGEF. Nat. Cell Biol. 11:1421-1426. http://dx.doi.org/10.1038/ncb1989

Nishihama, R., J.H. Schreiter, M. Onishi, E.A. Vallen, J. Hanna, K. Moravcevic, M.F. Lippincott, H. Han, M.A. Lemmon, J.R. Pringle, and E. Bi. 2009. Role of Inn 1 and its interactions with Hof 1 and Cyk3 in promoting cleavage furrow and septum formation in S. cerevisiae. J. Cell Biol. 185:9951012. http://dx.doi.org/10.1083/jcb.200903125

Noji, T., T. Yamamoto, K. Saito, K. Fujimura-Kamada, S. Kondo, and K. Tanaka. 2006. Mutational analysis of the Lem3p-Dnf1p putative phospholipid-translocating P-type ATPase reveals novel regulatory roles for Lem3p and a carboxyl-terminal region of Dnf1p independent of the phospholipid-translocating activity of Dnflp in yeast. Biochem. Biophys. Res. Commun. 344:323-331. http://dx.doi.org/10.1016/j.bbrc.2006.03.095

Oh, Y., and E. Bi. 2011. Septin structure and function in yeast and beyond. Trends Cell Biol. 21:141-148. http://dx.doi.org/10.1016/j.tcb.2010.11.006

Okada, S., M. Leda, J. Hanna, N.S. Savage, E. Bi, and A.B. Goryachev. 2013. Daughter cell identity emerges from the interplay of Cdc42, septins, and exocytosis. Dev. Cell. 26:148-161. http://dx.doi.org/10.1016/j.devcel .2013 .06 .015

Okuzaki, D., S. Tanaka, H. Kanazawa, and H. Nojima. 1997. Gin4 of S. cerevisiae is a bud neck protein that interacts with the Cdc28 complex. Genes Cells. 2:753-770. http://dx.doi.org/10.1046/j.1365-2443.1997.1590358.x

Onishi, M., N. Ko, R. Nishihama, and J.R. Pringle. 2013. Distinct roles of Rho1, Cdc42, and Cyk3 in septum formation and abscission during yeast cytokinesis. J. Cell Biol. 202:311-329. http://dx.doi.org/10.1083/ jcb.201302001

Pomorski, T., R. Lombardi, H. Riezman, P.F. Devaux, G. van Meer, and J.C. Holthuis. 2003. Drs2p-related P-type ATPases Dnf1p and Dnf2p are required for phospholipid translocation across the yeast plasma membrane and serve a role in endocytosis. Mol. Biol. Cell. 14:1240-1254. http:// dx.doi.org/10.1091/mbc.E02-08-0501

Roelants, F.M., A.G. Baltz, A.E. Trott, S. Fereres, and J. Thorner. 2010. A protein kinase network regulates the function of aminophospholipid flippases. Proc. Natl. Acad. Sci. USA. 107:34-39. http://dx.doi.org/10.1073/ pnas.0912497106

Roelants, F.M., D.K. Breslow, A. Muir, J.S. Weissman, and J. Thorner. 2011. Protein kinase Ypk1 phosphorylates regulatory proteins Orm1 and
Orm2 to control sphingolipid homeostasis in Saccharomyces cerevisiae. Proc. Natl. Acad. Sci. USA. 108:19222-19227. http://dx.doi.org/10 .1073/pnas.1116948108

Saito, K., K. Fujimura-Kamada, N. Furuta, U. Kato, M. Umeda, and K. Tanaka. 2004. Cdc50p, a protein required for polarized growth, associates with the Drs2p P-type ATPase implicated in phospholipid translocation in Saccharomyces cerevisiae. Mol. Biol. Cell. 15:3418-3432. http://dx.doi .org/10.1091/mbc.E03-11-0829

Saito, K., K. Fujimura-Kamada, H. Hanamatsu, U. Kato, M. Umeda, K.G. Kozminski, and K. Tanaka. 2007. Transbilayer phospholipid flipping regulates $\mathrm{Cdc} 42 \mathrm{p}$ signaling during polarized cell growth via Rga GTPase-activating proteins. Dev. Cell. 13:743-751. http://dx.doi.org/10 1016/j.devcel.2007.09.014

Sambrook, J., E.F. Fritsh, and T. Maniatis. 1989. Molecular Cloning: A Laboratory Manual. Cold Spring Harbor Lab Press, Cold Spring Harbor, NY. 1626 pp.

Schmidt, M., B. Bowers, A. Varma, D.H. Roh, and E. Cabib. 2002. In budding yeast, contraction of the actomyosin ring and formation of the primary septum at cytokinesis depend on each other. J. Cell Sci. 115:293-302.

Sebastian, T.T., R.D. Baldridge, P. Xu, and T.R. Graham. 2012. Phospholipid flippases: building asymmetric membranes and transport vesicles. Biochim. Biophys. Acta. 1821:1068-1077. http://dx.doi.org/10.1016/j.bbalip.2011 .12 .007

Shaner, N.C., R.E. Campbell, P.A. Steinbach, B.N. Giepmans, A.E. Palmer, and R.Y. Tsien. 2004. Improved monomeric red, orange and yellow fluorescent proteins derived from Discosoma sp. red fluorescent protein. Nat. Biotechnol. 22:1567-1572. http://dx.doi.org/10.1038/nbt1037

Sherman, F., G.R. Fink, and J.B. Hicks. 1986. Laboratory Course Manual for Methods in Yeast Genetics. Cold Spring Harbor Lab Press, Cold Spring Harbor, NY. 186 pp.

Shulewitz, M.J., C.J. Inouye, and J. Thorner. 1999. Hsl7 localizes to a septin ring and serves as an adapter in a regulatory pathway that relieves tyrosine phosphorylation of Cdc28 protein kinase in Saccharomyces cerevisiae. Mol. Cell. Biol. 19:7123-7137.

Sutton, A., D. Immanuel, and K.T. Arndt. 1991. The SIT4 protein phosphatase functions in late $\mathrm{G} 1$ for progression into $\mathrm{S}$ phase. Mol. Cell. Biol. $11: 2133-2148$.

Szkotnicki, L., J.M. Crutchley, T.R. Zyla, E.S. Bardes, and D.J. Lew. 2008. The checkpoint kinase Hsl1p is activated by Elm1p-dependent phosphorylation. Mol. Biol. Cell. 19:4675-4686. http://dx.doi.org/10.1091/mbc E08-06-0663

Tabb, D.L., W.H. McDonald, and J.R. Yates III. 2002. DTASelect and Contrast: tools for assembling and comparing protein identifications from shotgun proteomics. J. Proteome Res. 1:21-26. http://dx.doi.org/10.1021/pr015504q

Tanaka, K., K. Fujimura-Kamada, and T. Yamamoto. 2011. Functions of phospholipid flippases. J. Biochem. 149:131-143. http://dx.doi.org/10.1093/jb/ mvq140

Tjandra, H., J. Compton, and D. Kellogg. 1998. Control of mitotic events by the Cdc42 GTPase, the Clb2 cyclin and a member of the PAK kinase family. Curr. Biol. 8:991-1000. http://dx.doi.org/10.1016/S0960-9822(07)00419-8

Tong, Z., X.D. Gao, A.S. Howell, I. Bose, D.J. Lew, and E. Bi. 2007. Adjacent positioning of cellular structures enabled by a Cdc42 GTPase-activating protein-mediated zone of inhibition. J. Cell Biol. 179:1375-1384. http:// dx.doi.org/10.1083/jcb.200705160

Tsien, R.Y. 1998. The green fluorescent protein. Annu. Rev. Biochem. 67:509544. http://dx.doi.org/10.1146/annurev.biochem.67.1.509

Vallen, E.A., J. Caviston, and E. Bi. 2000. Roles of Hof1p, Bni1p, Bnr1p, and myolp in cytokinesis in Saccharomyces cerevisiae. Mol. Biol. Cell. 11:593-611. http://dx.doi.org/10.1091/mbc.11.2.593

van der Mark, V.A., R.P. Elferink, and C.C. Paulusma. 2013. P4 ATPases: flippases in health and disease. Int. J. Mol. Sci. 14:7897-7922. http://dx.doi org/10.3390/ijms14047897

van Meer, G. 2011. Dynamic transbilayer lipid asymmetry. Cold Spring Harb. Perspect. Biol. 3:a004671. http://dx.doi.org/10.1101/cshperspect.a004671

Yamane-Sando, Y., E. Shimobayashi, M. Shimobayashi, Y. Kozutsumi, S. Oka, and H. Takematsu. 2014. Fpk1/2 kinases regulate cellular sphingoid long-chain base abundance and alter cellular resistance to LCB elevation or depletion. Microbiologyopen. 3:196-212. http://dx.doi.org/ $10.1002 / \mathrm{mbo} 3.160$

Yoshida, S., S. Bartolini, and D. Pellman. 2009. Mechanisms for concentrating Rho1 during cytokinesis. Genes Dev. 23:810-823. http://dx.doi.org/ 10.1101/gad.1785209

Zhao, M. 2011. Lantibiotics as probes for phosphatidylethanolamine. Amino Acids. 41:1071-1079. http://dx.doi.org/10.1007/s00726-009-0386-9 